\title{
Dynamic resource allocation to support oil spill response planning for energy exploration in the Arctic
}

\author{
Richard A. Garrett ${ }^{a, *}$, Thomas C. Sharkey ${ }^{\mathrm{a}}$, Martha Grabowski ${ }^{\mathrm{a}, \mathrm{b}}$, William A. Wallace ${ }^{\mathrm{a}}$ \\ ${ }^{a}$ Industrial and Systems Engineering, Rensselaer Polytechnic Institute \\ $1108^{\text {th }}$ Street, Troy, NY 12180, USA \\ ${ }^{b}$ Madden School of Business, Le Moyne College \\ 1419 Salt Springs Road, Syracuse, NY 13214, USA
}

\begin{abstract}
A mixed-integer linear program is proposed to model the dynamic network expansion problem of improving oil spill response capabilities to support energy exploration in the Arctic. Oil spill response operations in this region can be hampered by a lack of existing infrastructure, limited pre-positioned response equipment, and the possibility that response equipment might not arrive in time to mitigate the impact of a spill because of distance and infrastructure limitations. These considerations are modeled by two inter-related constraint sets with the objective of minimized total weighted response time for a set of potential oil spill incidents. One constraint set determines how to dynamically allocate response equipment and improve the infrastructures necessary to stockpile them within a network of response sites. The other set determines how to utilize this stockpile to respond to each task necessary for an incident by scheduling the equipment to complete tasks. These task completion times are subject to deadlines which, if not met, can, instead, require costlier follow-on tasks to be scheduled. The model, its assumptions, and data requirements were assessed by subject matter experts in the United States (U.S.) Coast Guard and a major Oil Spill Response Organization in the context of oil spill response logistics to support energy exploration initiatives in the U.S. Arctic.
\end{abstract}

Keywords: OR in disaster relief, Decision analysis, Scheduling, OR in government

\section{Introduction}

Planning, prevention, and response activities for sudden-onset extreme events are challenging, and consume large portions of federal, state, and municipal budgets and time; in FY2014, the United States (U.S.) Department of Homeland Security alone allocated $\$ 13.45$ billion for these activities (U.S. Department of Homeland Security, 2013). In this paper, the focus is on oil spill response in the U.S. Arctic. Energy

\footnotetext{
*Corresponding author

Email addresses: garrer3@rpi .edu (Richard A. Garrett), sharkt@rpi .edu (Thomas C. Sharkey), grabowsk@lemoyne.edu (Martha Grabowski), wallaw@rpi.edu (William A. Wallace)
}

Preprint submitted to Elsevier

July 5, 2016 
exploration and growing maritime activity due to increasingly ice-free navigational waters have led to concerns over the region's capability to manage a major oil spill disaster (Papp. 2013; National Academy of Sciences, 2014). A mixed integer linear program is proposed to address the unique challenges of oil spill response in the U.S. Arctic and similar remote regions; this model provides decision-makers with new computational tools that examine how the dynamics of pre-staging equipment and improving response site infrastructures impact incident response times. This is believed to be the first model to incorporate the consequences of missed deadlines in terms of needing to complete a different task to mitigate the impact of the missed deadline.

This paper begins by describing this problem and presents a set of case study questions that guided the development of the case study and results. Section 3 describes previous work to develop related models for oil spill response, and the limitations and challenges of applying this earlier work to the Arctic. Section 4 introduces terminology, describes the model, and provides tables of notation. Section 5 discusses the method to generate test instances from a realistic case study of the Arctic. Computational difficulty of these tests is discussed (Section 6), and their results are presented (Section 7). The Online Appendix provides additional assumptions along with the complete model.

\section{Problem Description}

The Beaufort and Chukchi Seas in the Alaskan Arctic are estimated to contain a combined 90 billion barrels of oil, 1,670 trillion cubic feet of natural gas, and 44 billion barrels of natural gas liquids, in total accounting for $22 \%$ of the world's undiscovered and recoverable energy resources (Bird et al., 2008). Economic incentives to recover these resources have led to significantly increased maritime traffic and the potential for seasonal offshore drilling to occur, spurring interest in examining resource allocation challenges pertaining to the region's oil spill response capability (National Academy of Sciences, 2014. Huntington et al. 2015: National Petroleum Council, 2015). Issues concerning the lack of deepwater ports, few roads, and limited air and maritime navigational infrastructure, combined with few potential storage locations and extreme seasonal environmental conditions, complicate these challenges, including the supply, access, and deployment of emergency response equipment (Brigham, 2010; National Academy of Sciences. 2014). Figure 1 (National Academy of Sciences, 2014) shows the offshore energy exploration, planning, and development areas in the Arctic relative to the small number of sparsely populated villages in which Arctic oil spill response infrastructure resides.

Resource allocation challenges associated with a large oil spill incident from vessel spills and oil drilling operations are of concern to Arctic decision-makers (U.S. Department of the Interior, Bureau of Ocean Energy Management, 2011a b; :United States Coast Guard, 2013). Arctic oil spill response requires the deployment of oil spill response equipment, or resources, such as oil absorbent boom, skimmers, and maritime vessels, in order to complete tasks, the pieces of work necessary to restore an affected region to normalcy (Alaska Clean Seas, 2012, 2013). However, any planned response is often reliant on private 


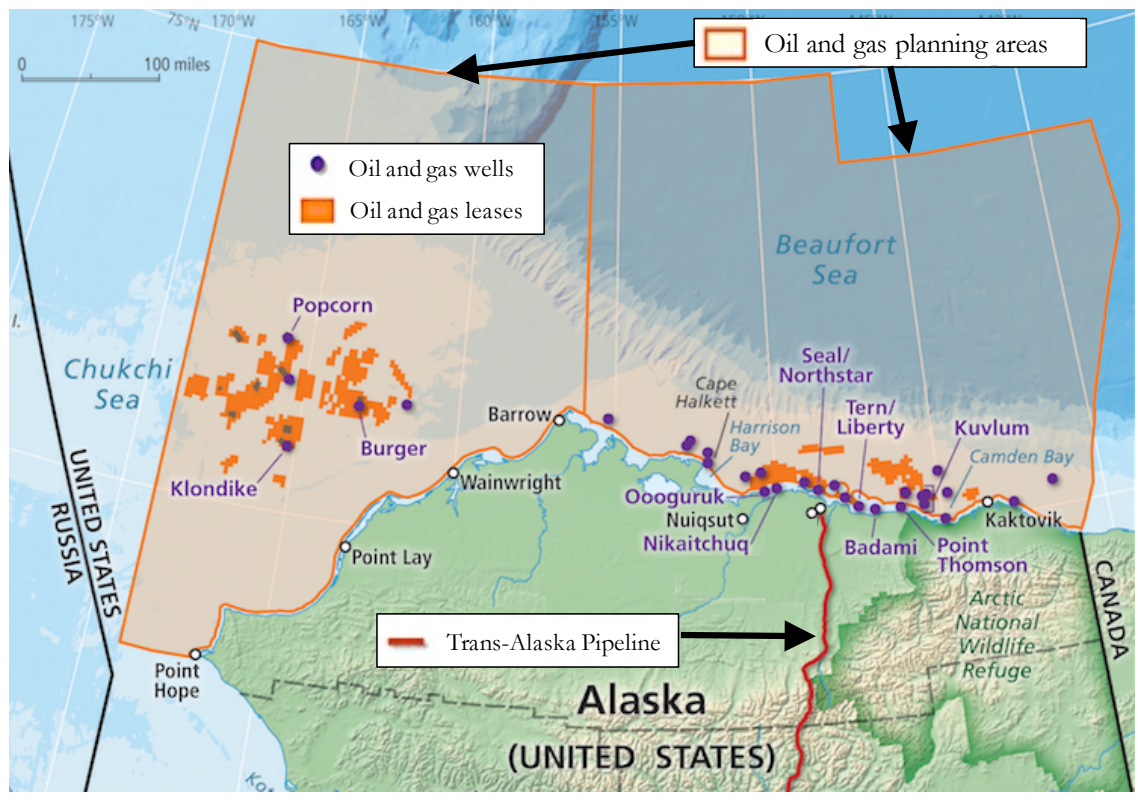

Figure 1: Oil and gas wells, leases, and planning areas in northernmost Alaska (National Academy of Sciences. 2014).

industry resources under current oil spill contingency plans (U.S. Department of the Interior, Bureau of Ocean Energy Management, 2011a b; Hamilton et al., 2012, Alaska Clean Seas, 2012, 2013). Arctic decision-makers are concerned with how to stockpile these resources and improve the infrastructure in Arctic communities; how these stockpiles influence resource deployments and improve spill response; and how these decisions help ensure an effective response.

The oil spill response sites, formed by Alaskan communities that stockpile resources within their infrastructure and mobilize them to complete tasks during a response, are modeled as a network. Resource allocation models for networks of Arctic response sites must address challenges regarding seasonality, location, scale, and scope. Decision-makers are interested in four key concerns related to these challenges: (i) reliance on a few remote response sites to mobilize resources for deployment at a potential spill incident; (ii) dynamics involving fluctuations in resource stockpiles; (iii) lack of sufficient mobilization capacity at each response site (e.g., a site's ability to prepare resources for transit to the spill incident), and task completion capacity at each incident location (e.g., the ability to concurrently complete tasks at an incident); and (iv) limited budgets to build infrastructure to store response resources (e.g., booms, skimmers, vessels, etc.). These concerns motivate the case study (CS) questions, which influence the model's formulation and focus the computational tests and sensitivity analyzes of the case study:

CS1: What are the impacts on response times of budgetary limitations?

CS2: How does geographic position within the response network influence the scale and scope of a stockpile? 
CS3: What is the optimal stockpile improvement policy?

CS4: What is the optimal infrastructure investment policies?

CS5: How do bottlenecks and delayed resource deployments impact the solution?

CS6: What are optimal task completion policies?

CS7: How does the inclusion of additional response sites impact the solution?

Prior research on related problems is considered in order to determine the basis for the modeling efforts.

\section{Relevant Past Research}

Prior work has examined resource allocation in the context of oil spill response using goal-, mixedinteger-, and stochastic-programming, as well as econometric models. This work has assumed that response resources can be sited in proximity to an incident, such that the assumption of an adequate on-time response is valid. Charnes et al. (1976, 1979) conducted work that developed goal-programming models for U.S. Coast Guard resource allocation decisions for marine environment protection and evaluated resource type planning policies for marine pollution disasters. Belardo et al. (1984) developed a multiobjective set-covering model for evaluating response resource siting policies that focused on minimizing the probability of potential oil spill occurrence. Psaraftis et al. (1986) developed a mixed-integer programming resource allocation model for oil spill incident response that focused on building facilities to hold response resources and then acquiring appropriate equipment for response. Srinivasa \& Wilhelm (1997) developed a multiperiod integer program for oil spill response resource allocation that measures response time by the total minimized time required to respond. Iakovou et al. (1997) developed a non-dynamic, deterministic integer-programming model for oil spill response resource allocation that selects the optimal number of facility sites, amount and type of material, and dispatching policies. Gawande \& Wheeler (1999) modeled the statistical expectation of response time of the U.S. Coast Guard Maritime Safety Program by way of probit- and Poisson-based econometric models. Verma et al. (2013) extended the work of Psaraftis et al. (1986) and Iakovou et al. (1997) by developing a two-stage stage stochastic model that pre-positions response equipment to meet uncertainty in spill occurrence and characteristics.

\subsection{Concerning Remote Regions}

Previous work (e.g., Psaraftis et al. (1986); Srinivasa and Wilhelm (1997); Iakovou et al. (1997); Verma et al. (2013)), while methodologically similar to ours, does not account for resource allocation for remote incident response networks such as those in the Arctic. Earlier work assumed that there was at least one site that could send resources to a particular oil spill incident within a critical time window. However, this assumption does not hold for remote response networks, where resources are potentially subject to significantly long transit times. Prior work typically assumed the response network was sufficiently capable and ignored the consequences of an insufficient response, which is more likely to occur in remote and infrastructure-limited networks. Dynamics concerning the configuration of resource stockpiles, the number 
and type of resources on-hand at all sites within the response network, were assumed to be insignificant. Certain remote regions face environmental conditions that can prohibit actions during one or more seasons and necessarily limit stockpile reconfiguration decisions at those times. These regions therefore must incorporate seasonal dynamics into the decision making process. Finally, much of the prior research focused on minimizing costs incurred during a response effort instead of increasing response capabilities subject to budgetary limitations in order to minimize response times. Resource allocation is addressed differently from Psaraftis et al. (1986) given the dynamic nature of the decisions, and the potential to begin by introducing a particular capability via infrastructure construction decisions. The possibility of resource stockpile reconfigurations in response to seasonal changes is also considered, thus improving applicability of the work to the Arctic problem. The oil spill response aspects are distinct from those found in Iakovou et al. (1997) and Verma et al. (2013) in order to enable examination of the consequences due to insufficient capability resulting from remote and infrastructure-limited response networks. A mixed-integer linear program is developed that supports dynamic resource allocation and network improvement decisions in remote regions and considers the impacts of failing to adequately respond, leveraging earlier work in oil spill modeling by (Charnes et al., 1976, 1979), maritime risk (Harrald et al., 1999: Merrick et al., 2000. Grabowski et al. 2010), and recent analysis in dynamic network restoration and expansion (Romeijn et al. 2010: Sharkey et al., 2011: Nurre et al., 2012: Averbakh, 2012; Averbakh and Pereira, 2012, Cavdaroglu et al., 2013: Qiu and Sharkey, 2013; Nurre and Sharkey, 2014; Baxter et al., 2014; Forbes, 2015; Kalinowski et al. 2015: Averbakh and Pereira, 2015). This approach is applied to the case of oil spill response in the Alaskan Arctic, a region which demonstrates the criticality of the aforementioned assumptions.

\section{Model Overview}

In this section, the model is described by introducing relevant terminology and notation. The mathematical formulation is presented in the sections to follow. Set definitions are presented in Table 1 . variable definitions are presented in Table 2 , and parameter definitions are presented in Table 3 A mixedinteger linear program is formulated by two inter-related constraint sets to address the resource allocation challenges faced by an Arctic oil spill response network: the resource allocation component and the oil spill response component. The two components work together to allocate resources dynamically throughout a network of response sites to create "stockpiles" and then provide the weighted response times generated by using those stockpiles to respond to a set of potential oil spill incidents. The resource allocation component modifies the stockpile configuration across a resource allocation time horizon. Stockpile configuration decisions

for each potential incident improve the response produced by the oil spill response component. The oil spill response component produces a task schedule by minimizing the weighted response times of completing all necessary tasks across a incident response time horizon, subject to the resources required and their deployment times and positions within the stockpiles of the response network. The objective of best possible weighted response times is considered for each of the potential incidents occurring in one or more time periods of 
the resource allocation time horizon. The model was vetted with subject matter experts in Arctic oil spill response in the U.S. Coast Guard and in a key oil spill response organization operating in the region.

The oil spill response component models the decisions necessary to complete the tasks for each potential incident response by utilizing resources stockpiled within one or more response sites. Figure 2 illustrates the timeline of activities for a resource of type $i$ located at site $j$ to be used in response to incident e. First, the resource is mobilized at site $j$, whereby the resource is prepared for transport to the incident location. Then, the resource spends time in transit from site $j$ to the incident location. Next, the resource is deployed for use with the task, and the point in time when this process has finished is considered as the resource's deployment time. Last, the task is completed, whereby all resources it requires have been deployed and the task's activity may commence. The point in time when this process has finished is considered as the task's completion time, which is equivalent to the resource's deployment time for tasks requiring a single resource. For a particular incident, the total weighted response time is the sum of the product of the task completion times and their weights.

Timeline for Resource $i$ to be used in Incident Response

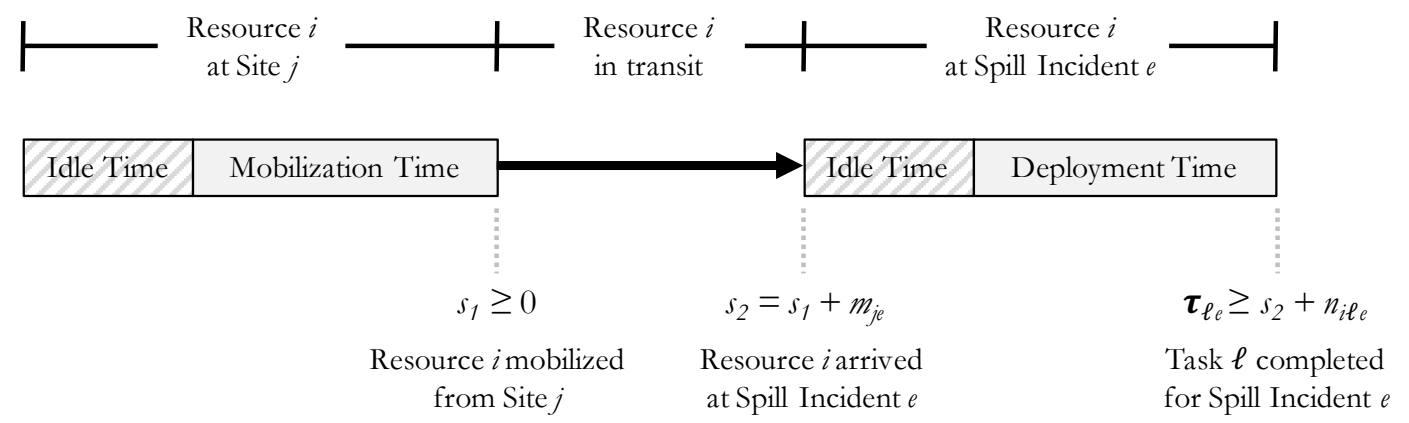

Figure 2: The timeline of activities for resource $i$ to be used for task $\ell$ in response to incident $e$. Time $s_{1}$ : resource $i$ has been mobilized for transport to incident $e$ from response site $j$, and idle time can be introduced by the mobilization capacity of site $j$. Time $s_{2}$ : resource $i$ has arrived at the spill incident after the time required to transport it from the response site $\left(m_{j e}\right)$. Time $s_{3}$ : task $\ell$ is completed $\left(\tau_{\ell \ell}\right)$ after the time required to deploy resource $i$ for the task at the incident $\left(n_{i \ell e}\right)$. Here, idle time can be introduced (i) if time was spent waiting for other resources to arrive, (ii) due to the capacities at the incident site, or (iii) due to the time spent completing the safety task. Notes: (a) a resource's mobilization time is assumed to equal one for all resources; (b) the task's completion time is equivalent to the resource's deployment time for tasks requiring a single resource.

The completion time of a task depends on the time required to transport and deploy the resources arriving from one (or more) response sites, and on certain factors which can cause delays or bottlenecks. These factors include: (i) resource mobilization capacity, the number of resources which can be mobilized at a response site for transport to an incident location per time period; (ii) task completion capacity, the number of tasks which can be in their completion process at the incident site per time period; and (iii) prior completion of the safety task before completing certain other tasks, which represents the operations dedicated to preserving human safety and declaring the incident site suitable for conducting a response 
effort. These factors can cause the idle time illustrated in Figure 2.

Task pairs model the consequences due to oil spread, and the resulting additional effort required to restore shoreline areas, if certain tasks are completed late. These pairs include certain initial tasks that have a deadline which, if not met, require the completion of follow-on tasks, instead. The resources required for a follow-on task are the sum of those required for the paired initial task, combined with the resources required for shoreline cleanup operations. Deadlines are generated for all initial tasks as determined by the amount of time estimated until shoreline impact in order to generate the resource requirements for their follow-on tasks (Aagaard et al., 1989. MBC Applied Environmental Sciences, 2003; Danielson et al., 2006: Alaska Clean Seas, 2012, 2013: Hongxia et al., 2013). For example, an incident might require a recovery task to be completed before day 6, when the spillage would otherwise come ashore and require a follow-on shoreline cleanup task in addition to what has already been completed. In this example, the follow-on task would require the same resources as its paired initial task (e.g., the recovery task) plus the additional resources required if the deadline were missed (e.g., the shoreline cleanup task) in order to incorporate the effort made for tasks completed pre- and post-deadline. Since the resources required for the initial task are also required for the follow-on task, the task pair structure can be considered as modeling the arrival of resources to the spill incident which remain on location until they can cumulatively be used to complete the initial task. Note, however, that the model can determine whether a deadline will be missed for an initial task, and it may elect not to deploy the necessary resources even if this task's deadline is attainable (in favor of deploying resources for other initial tasks that will meet their deadlines), so that the resources arrive at the same time as the resource that causes a bottleneck in the completion of the initial task. This is believed to be the first model to examine consequences of missed deadlines in terms of needing to complete a different task to mitigate the impact of the missed deadline.

Decisions from the resource allocation component impact the amount of resources available to the response network via stockpile configuration decisions and infrastructure investment decisions. Stockpile configuration decisions can be manipulated through resource allocation decisions, including transporting a resource between response sites, purchasing, or retaining until the next time period. Infrastructure investment decisions make improvements to two distinct infrastructure design option classes by deciding the options that are currently available and whether to invest. These design options include: capability options, which allow for pre-staging certain resources; and capacity options, which improve storage capacity for certain resources. Expert opinion noted that, while a resource is stored in only one capacity class, it can require multiple capability classes. For example, a landing strip, refueling depot, and aircraft hangar may be constructed in a response site. The addition of the landing strip and refueling depot would provide the response site with the capability to store aircraft, and the hangar would provide the site with the capacity to store multiple aircraft.

The remainder of this section is organized as follows. Section 4.1 discusses the objective of minimizing total weighted response time for the set of potential oil spill incidents. Section 4.2 introduces the oil spill response constraints and discusses the decisions necessary to generate the task schedule for a response to an 
incident. Section 4.3 introduces the resource allocation constraints that influence the stockpile configuration which impact the responses to incidents. Theoretical complexity of the model is discussed in Section 4.4 .

Table 1: Set Definitions

\begin{tabular}{ll}
\hline Set Name & Definition \\
\hline$E_{t}$ & the spill incidents, occurring at each time period $t \in T$. \\
$L$ & the tasks. \\
$P$ & the task pairs. \\
$T$ & the resource allocation time periods. \\
$S$ & the incident response time periods. \\
$I$ & the resources. \\
$O^{C B}$ & the capability design options. \\
$O^{C P}$ & the capacity design options. \\
$I(o)$ & the set of resources requiring either design option $o \in O^{C B}$ or \\
& $o \in O^{C P}$ in order to be stored in a response site. \\
$J$ & the response sites.
\end{tabular}

Table 2: Variable Definitions

\begin{tabular}{|c|c|}
\hline Variable Name & Definition \\
\hline$\pi_{l_{1} \text { et }}$ & $\begin{array}{l}\text { whether initial task } l_{1} \in L \text { or follow-on task } l_{2} \in L \text {, each of task pair }\left(l_{1}, l_{2}\right) \in P \text {, is } \\
\text { completed for spill incident } e \text { at time period } t \text {. If initial task } l_{1} \in L \text { is completed (i.e. } \\
\text { its deadline is met), then } \pi_{l_{1} e t}=1, \pi_{l_{1} \text { et }}=0 \text { otherwise. }\end{array}$ \\
\hline$\tau_{\text {let }}$ & $\begin{array}{l}\text { the completion time of task } l \text { for spill incident } e \text { at time period } t \text {. Completion times } \\
\text { are measured in units of incident response time periods }(s \in S) \text {. }\end{array}$ \\
\hline$\delta_{i j l e s t}$ & $\begin{array}{l}\text { whether resource } i \text { is mobilized from response site } j \text { for task } l \text { for spill incident } e \text { in } \\
\text { incident response period } s \text { at time period } t \text {. }\end{array}$ \\
\hline$\Delta_{\text {lest }}$ & $\begin{array}{l}\text { whether task } l \text { is completed for spill incident } e \text { during incident response time period } \\
s \text { at resource allocation time period } t \text {. If task } l \text { is completed, then } \Delta_{\text {lest }}=1, \Delta_{\text {lest }}=0 \\
\text { otherwise. }\end{array}$ \\
\hline$\zeta_{i j l e t}$ & $\begin{array}{l}\text { whether resource } i \text { has been transported from response site } j \text { to be deployed for task } \\
l \text { for spill incident } e \text { at time period } t \text {. If resource } i \text { is transported and deployed, then } \\
\zeta_{\text {ijlet }}=1, \zeta_{\text {ijlet }}=0 \text { otherwise. }\end{array}$ \\
\hline$\chi_{i j e l t}$ & $\begin{array}{l}\text { the amount of resource } i \text { mobilized from response site } j \text { to spill incident } e \text { for task } l \\
\text { at time period } t \text {. }\end{array}$ \\
\hline$v_{\text {est }}$ & $\begin{array}{l}\text { whether the safety task } f \text { has been completed by capacity period } s \text { in response } \\
\text { to spill } e \text { at time period } t \text {. If task } f \text { has been completed, then } v_{\text {est }}=1, v_{\text {est }}=0 \\
\text { otherwise. }\end{array}$ \\
\hline$\Omega_{i j t}$ & the amount of resource $i$ on hand in response site $j$ at time period $t$. \\
\hline$\alpha_{\text {jot }}$ & $\begin{array}{l}\text { whether infrastructure capability option } o \in O^{C B} \text { is available in response site } j \text { at } \\
\text { time period } t \text {. If design option } o \in O^{C B} \text { is available, then } \alpha_{j o t}=1, \alpha_{j o t}=0 \text { otherwise. }\end{array}$ \\
\hline$\beta_{\text {jot }}$ & $\begin{array}{l}\text { whether infrastructure capability option } o \in O^{C B} \text { is built in response site } j \text { at time } \\
\text { period } t \text {. If design option } o \in O^{C B} \text { is built, then } \beta_{\text {jot }}=1, \beta_{\text {jot }}=0 \text { otherwise. }\end{array}$ \\
\hline
\end{tabular}


Table 2 - continued from previous page

\begin{tabular}{|c|c|}
\hline Variable Name & Definition \\
\hline$\lambda_{\text {jot }}$ & $\begin{array}{l}\text { the amount of infrastructure capacity option } o \in O^{C P} \text { currently available in response } \\
\text { site } j \text { for } o \in O^{C P} \text { at time period } t \text {. }\end{array}$ \\
\hline$\Lambda_{\text {jot }}$ & $\begin{array}{l}\text { the amount of infrastructure capacity option } o \in O^{C P} \text { to build in response site } j \text { for } \\
o \in O^{C P} \text { at time period } t \text {. }\end{array}$ \\
\hline$\phi_{i j t}$ & the amount of resource $i$ purchased in response site $j$ between periods $t-1$ and $t$. \\
\hline$\sigma_{i j k t}$ & $\begin{array}{l}\text { the amount of resource } i \text { shipped from response site } j \text { to response site } k \text { between } \\
\text { periods } t-1 \text { and } t \text {. }\end{array}$ \\
\hline$\psi_{i j t}$ & the amount of resource $i$ to be held in response site $j$ from time period $t-1$ to $t$. \\
\hline
\end{tabular}

Table 3: Parameter Definitions

\begin{tabular}{|c|c|}
\hline Parameter Name & Definition \\
\hline$A_{t}$ & $\begin{array}{l}\text { the spending budget for resource purchasing, shipping, and lifecycle costs at time } \\
\text { period } t \text {. }\end{array}$ \\
\hline$a_{i j t}^{1}$ & the purchasing cost of resource $i$ in response site $j$ at time period $t$. \\
\hline$a_{i j k t}^{2}$ & $\begin{array}{l}\text { the shipping cost of resource } i \text { from response site } j \text { to response site } k \in J \text { at time } \\
\text { period } t \text {. }\end{array}$ \\
\hline$a_{i j}^{3}$ & the maintenance cost of resource $i$ in response site $j$. \\
\hline$B_{t}$ & the spending budget for infrastructure expansion at time period $t$. \\
\hline$b_{\text {jot }}$ & $\begin{array}{l}\text { the infrastructure expansion cost in response site } j \text { for design option } o \text { at time period } \\
t \text {. }\end{array}$ \\
\hline$c_{j o t}$ & the capacity for resource $i$ in response site $j$ of design option $o$. \\
\hline$d_{l e}$ & e deadline required to complete task $l$ for spill incident $e$. \\
\hline$f$ & e safety task within $L$. \\
\hline $\begin{array}{l}g_{i l} \\
\left(l_{1}, l_{2}\right)\end{array}$ & $\begin{array}{l}\text { the number of units of deployment capacity required to deploy resource } i \text { for task } l \text {. } \\
\text { a pair of tasks wherein if the deadline for initial task } l_{1} \text { is missed, then the completion } \\
\text { of follow-on task } l_{2} \text { is required, instead. If the deadline is met for } l_{1} \text {, then the } \\
\text { completion of } l_{2} \text { is unnecessary. }\end{array}$ \\
\hline$m_{j e}$ & $\begin{array}{l}\text { the transport time required for resources from response site } j \text { arriving at spill } \\
\text { incident } e \text {. }\end{array}$ \\
\hline$n_{\text {ilet }}$ & the time required to deploy resource $i$ for task $l$ for spill incident $e$ at time $t$. \\
\hline$r_{i l e}$ & the amount of resource $i$ required for task $l$ in response to spill incident $e$. \\
\hline$u_{j}$ & $\begin{array}{l}\text { the upper bound on the number of mobilized resources from response site } j \text { during } \\
\text { incident response time period } s \text {. }\end{array}$ \\
\hline$u_{e}$ & $\begin{array}{l}\text { the upper bound on the number of tasks that can be processed for completion at } \\
\text { spill incident } e \text { during incident response time period } s \text {. }\end{array}$ \\
\hline$w_{\text {let }}$ & the weight for completing task $l$ in response to spill $e$ at time period $t$. \\
\hline$z_{i o}$ & size of resource $i$ for design option $o$. \\
\hline
\end{tabular}

\subsection{Objective Function}

The objective function is to minimize the total weighted completion times of each task $l \in L$ required in the response to each incident $e \in E_{t}$ occurring in time period $t$. This completion time is represented by 
$\tau_{\text {let }}$, and $w_{\text {let }}$ can weight the completion time for incident $e$ and/or task $l$ in order to increase the priority of responding to an incident, completing a task, or both. For example, increased weight can be applied to incidents having higher likelihoods of occurrence, or to certain tasks that are more critical. The resulting problem is similar to that of minimizing total weighted completion times (see, for instance, (Pinedo, 2008)), with a few novel aspects which are discussed throughout this section. The objective function is expressed as

$$
\min \sum_{l \in L} \sum_{e \in E_{t}} \sum_{t \in T} w_{l e t} \tau_{l e t}
$$

The decision variables denoting the completion time of a task $l$ for an incident $e$ at time period $t\left(\tau_{l e t}\right)$ depend directly on the oil spill response component (Section 4.2) and indirectly on the resource allocation component (Section 4.3).

\subsection{Oil Spill Response Component}

Each incident $e$ requires the completion of certain tasks from the set $l$ along the response time horizon $S$ in order to generate a value for $\tau_{\text {let }}$. These completions depend on the total time required to transport and prepare for use each necessary resource $i$ arriving from one (or more) sites $j$, given the conditions present at time period $t$ of the resource allocation time horizon. These decisions are impacted by the stockpile configuration decisions, the amount of resource $i \in I$ at response site $j \in J$ at time period $t \in T$ of the resource allocation horizon $\left(\Omega_{i j t}\right)$. For a specific incident, these variables then limit the decisions made by the oil spill response component in responding to a specific incident.

Task pairs $\left(l_{1}, l_{2}\right) \in P$ are used to model the impact of missing deadlines by way of linked initial $\left(l_{1} \in L\right)$ and follow-on $\left(l_{2} \in L\right)$ tasks, and the selected task defines the resources to mobilize from the response network $J$. Let $d_{l_{1} e}$ represent the deadline for initial task $l_{1}$ required for spill incident $e$, and $r_{i l e t}$ represent the amount of resource $i$ required for task $l$ of spill incident $e$. An initial task $l_{1}$ that is selected for completion $\left(\pi_{l_{1} e t}=1\right)$ must be done so by its deadline (Constraints 1 ). Failing to complete $l_{1}$ by its deadline $\left(1-\pi_{l_{1} e t}=1\right)$ results in follow-on task $l_{2}$ to be completed, instead (Constraints 2). The selected task (initial or follow-on) must have its required amount of resource $i\left(r_{\text {ilet }}\right)$ met by mobilizing resource $i$ from the stockpile of one or more sites $j$ in the response network (decisions $\chi_{i j l e t}$ ) which are expressed in Constraints 3, 4. The task deadlines and resource requirements constraints are expressed as

$$
\begin{aligned}
\tau_{l_{1} e t}-d_{l_{1} e} \pi_{l_{1} e t} & \leq 0 \text { for } l_{1} \in L, e \in E_{t}, t \in T, \\
\tau_{l_{2} e t}-\left(d_{l_{1} e}+1\right)\left(1-\pi_{l_{1} e t}\right) & \geq 0 \text { for }\left(l_{1}, l_{2}\right) \in P, e \in E_{t}, t \in T, \\
\sum_{j \in J} \chi_{i j l_{1} e t}-r_{i l_{1} e t} \pi_{l_{1} e t} & \geq 0 \text { for } i \in I, l_{1} \in L, e \in E_{t}, t \in T, \\
\sum_{j \in J} \chi_{i j l_{2} e t}-r_{i l_{2} e t}\left(1-\pi_{l_{1} e t}\right) & \geq 0 \text { for } i \in I,\left(l_{1}, l_{2}\right) \in P, e \in E_{t}, t \in T .
\end{aligned}
$$

In order for any amount of resource $i$ to be mobilized from site $j$ for use in task $l$ for incident $e \in E_{t}$ 
(variable $\chi_{i j l e t}$ ), it is necessary for that resource to be transported to the incident location and then deployed. The binary decision variable $\zeta_{i j l e t}$ will be equal to 1 should resource $i$ be transported from site $j$ for task $l$ at incident $e \in E_{t}$ and Constraints 5 enforce the relationship between $\zeta_{\text {ijlet }}$ and $\chi_{i j l e t}$. The amount of resource $i$ mobilized from site $j$ is limited by how much is currently stockpiled $\left(\Omega_{i j t}\right)$ which is modeled by Constraints 6 , and this amount is driven by the resource allocation decisions discussed in Section 4.3 . It is then necessary to decide the time period $s$ which resource $i$ will be mobilized from $j\left(\delta_{i j l e s t}=1\right.$ if we mobilize $i$ from $j$ in $s$ ). Constraints 7 enforce that should any amount of resource $i$ be transported from $j$ and deployed for task $l$ for $e \in E_{t}$, it must be mobilized in some time period $s \in S$. These resource mobilization and deployment constraints are expressed as

$$
\begin{aligned}
& \chi_{i j l e t}-r_{i l e t} \zeta_{i j l e t} \leq 0 \text { for } i \in I, j \in J, l \in L, e \in E_{t}, t \in T, \\
& \sum_{l \in L} \chi_{i j l e t}-\Omega_{i j t} \leq 0 \text { for } i \in I, j \in J, e \in E_{t}, t \in T, \\
& \zeta_{\text {ijlet }}-\sum_{s \in S} \delta_{i j l e s t} \leq 0 \text { for } i \in I, j \in J, l \in L, e \in E_{t}, t \in T .
\end{aligned}
$$

In order for task $l$ to be completed in time period $s$ for incident $e \in E_{t}\left(\Delta_{\text {lest }}=1\right)$, all of its required resources must be mobilized from their selected sites in the response network $\left(\delta_{i j l e s t}=1\right.$ for some site $j$ and period $s)$, transported to the location of the incident $\left(m_{i j e}\right)$, and then deployed at the incident $\left(n_{\text {ilet }}\right)$. Constraints 8 enforce this relationship based on whether site $j$ was selected for transporting resource $i$ for task $l\left(\zeta_{\text {ijlet }}\right)$. Constraints 9 then calculate the completion time of a task $\left(\tau_{\text {let }}\right)$ based on the selected time period of completion of task $l$, while Constraints 10 ensure that each task is only completed once. The completion time constraints are represented as

$$
\begin{aligned}
\left(m_{\text {ije }}+n_{\text {ilet }}\right) \zeta_{\text {ijlet }}+\sum_{s \in S}(s-1) \delta_{\text {ijlest }}-\sum_{s \in S} s \Delta_{\text {lest }} & \leq 0 \text { for } i \in I, j \in J, l \in L, e \in E_{t}, t \in T, \\
\tau_{\text {let }}-\sum_{s \in S} s \Delta_{\text {lest }} & \geq 0 \text { for } l \in L, e \in E_{t}, t \in T, \\
\sum_{s \in S} \Delta_{\text {lest }} & \leq 1 \text { for } l \in L, e \in E_{t}, t \in T .
\end{aligned}
$$

Additional considerations can delay the completion time of task $l$ (Figure 2): the resource mobilization capacity of site $j$, the task completion capacity at incident $e$, and the safety task's completion time. The capacity of site $j$ to mobilize resources simultaneously for all tasks $\left(u_{j}\right)$ is limited per response time period $s$ (Constraints 11). At incident $e$, the capacity to simultaneously process tasks for completion is limited $\left(u_{e}\right)$. Constraints 12 ensure that the number of units required for deploying resources at time $s$ does not exceed $u_{e}$. Note that task $l$ is currently being processed for completion if its resources are deployed from time $s$ through time $s+n_{\text {ilet }}-1$, and we assume that all resources required for task $l$ are deployed simultaneously. 
Experts noted that $u_{j}, u_{e}$ do not change seasonally, given the ability for work crews to manage the tasks required for different incidents occurring in different seasons (e.g., $e \in E_{t}$ ).

The safety task $f \in L$ must be completed prior to (safely) completing certain other tasks (where $v_{\text {est }}=1$ if this task is completed at or before s). If task $l \in L \backslash\{f\}$ is completed, then the safety task $f$ must have been previously completed with sufficient time to deploy its resources (Constraints 13). In order for the safety task $f$ to have been completed at or before time $s$, it must either have been completed at time $s$, or completed in the previous time period (Constraints 14). Additionally, the safety task must have been competed in the first time period $(s=1)$ for it to be completed at or before at that time (Constraints 15). Resource mobilization capacity, task completion capacity, and completion of the safety task prior to completing other tasks constraints are represented as follows

$$
\begin{aligned}
\sum_{i \in I} \sum_{l \in L} \delta_{i j l e s t}-u_{j} & \leq 0 \text { for } j \in J, e \in E_{t}, s \in S, t \in T, \\
\sum_{l \in L} \sum_{s^{\prime}=s}^{\min \left(s+n_{\text {ilet }}-1,|S|\right)} g_{i l} \Delta_{l e s^{\prime} t}-u_{e} & \leq 0 \text { for } i \in I, e \in E_{t}, s \in S, t \in T, \\
\Delta_{\text {lest }}-v_{e\left(d-n_{\text {ilet }}\right) t} & \leq 0 \text { for } l \in L \backslash\{f\}, e \in E_{t}, s \in S, t \in T, \\
v_{\text {est }}-\Delta_{\text {fest }}-v_{e(d-1) t} & =0 \text { for } f \in L, e \in E_{t}, s \in S, t \in T, \\
v_{e 1 t}-\Delta_{l e 1 t} & \leq 0 \text { for } e \in E_{t}, 1 \in S, t \in T .
\end{aligned}
$$

\subsection{Resource Allocation Component}

The resource allocation component decisions are made along a time horizon $T$, for a set of resources $I$ sited within a set of infrastructures $O$ across a set of response sites $J$. These decisions impact the task completion time, $\tau_{l e t}$, by altering the types and amounts of resources $i$ stockpiled in site $j, \Omega_{i j t}$. In each time period $t$, the resource allocation decisions are made by purchasing, transporting, and maintaining resources subject to budget level $A_{t}$. These decisions alter the flow balance of resources between time periods, and the stockpile configuration $\Omega_{i j t}$ is decided as a result. Resource $i$ can be stockpiled in response site $j$ at time period $t$ if it was previously transported to response site $k \in J\left(\sigma_{i j k t}\right)$, purchased $\left(\phi_{i j t}\right)$, or held over $\left(\psi_{i j t}\right)$. Then, the stockpile at time $t$ is equal to the in-flow of resource $i$ from the previous time period, which is the amount purchased and held-over in site $j$, and transported into site $j$ from site $k \in J: k \neq j$ (Constraints 16). The stockpile at time $t$ is also equal to the out-flow of resource $i$ at the current time period, which is the amount to be held over in site $j$ and transported out of site $j$ to site $k \in J: k \neq j$ (Constraints 17). The total

cost from the resource allocation decisions, from purchasing $\left(a_{i j t}^{1}\right)$, transporting $\left(a_{i j t}^{2}\right)$, and holding $\left(a_{i j t}^{3}\right)$, must be no greater than the resource allocation budget (Constraints 18). The resource allocation decisions are represented as

$$
\phi_{i j(t-1)}+\sum_{k \in J: k \neq j} \sigma_{i k j(t-1)}+\psi_{i j(t-1)}=\Omega_{i j t} \text { for } i \in I, j \in J, t \in T,
$$




$$
\begin{aligned}
\psi_{i j t}+\sum_{k \in J: k \neq j} \sigma_{i j k t} & =\Omega_{i j t} \text { for } i \in I, j \in J, t \in T, \\
\sum_{i \in I} \sum_{j \in J}\left\{a_{i j t}^{1} \phi_{i j t}+\sum_{k \in J: k \neq j} a_{i j k t}^{2} \sigma_{i k j t}+a_{i j}^{3} \psi_{i j t}\right\} & \leq A_{t} \text { for } t \in T .
\end{aligned}
$$

In response site $j$, each resource must be stockpiled within one class of capacity infrastructure options but may require multiple classes of capability infrastructure options. The investments made to build these infrastructures represent the dynamic network expansion decisions. Resource allocation decisions, and therefore $\Omega_{i j t}$, are impacted by the infrastructure at $j$ within the two distinct infrastructure design option classes: capability options $\left(O^{C B}\right)$; and capacity options $\left(O^{C P}\right)$. A resource is stored in one $O^{C P}$ class, but can require multiple $O^{C B}$ classes. Therefore, $I(o)$ is defined to be the set of resources that require option $o$ in order to be stored at site $j$, such that $I\left(o_{1}\right) \cap I\left(o_{2}\right)=\varnothing \forall\left(o_{1}, o_{2}\right) \in O^{C P}$.

Four variables comprise the set of infrastructure investment decisions. The number of capacity options $O^{C P}$ in site $j$ at time $t$ are determined by the number built $\left(\Lambda_{j o t}\right)$ in addition to the number available $\left(\lambda_{j o t}\right)$. The capability options $O^{C B}$ in site $j$ are determined similarly, where $o$ is built $\left(\beta_{j o t}=1\right)$ or is available $\left(\alpha_{\text {jot }}=1\right)$. For each infrastructure option $o$, the size of resource $i$ is defined $\left(z_{i o}\right)$, and must not exceed the storage capacity within that option $\left(c_{j o t}\right)$, where $c_{j o t}$ for $o \in O^{C B}$ acts as a 'Big- $M^{\prime}$ (Constraints 19, 21). The types of infrastructure in site $j$ at time $t$ depend on which options $o$ are available or built in the previous time period (Constraints 20, 22). The infrastructure investment decisions are represented as

$$
\begin{aligned}
\sum_{i \in I(o)} z_{i o} \Omega_{i j t}-c_{j o t} \lambda_{j o t} & \leq 0 \text { for } j \in J, o \in O^{C P}, t \in T, \\
\lambda_{j o(t-1)}+\Lambda_{j o(t-1)}-\lambda_{j o t} & =0 \text { for } j \in J, o \in O^{C P}, t \in T, \\
\sum_{i \in I(o)} z_{i o} \Omega_{i j t}-c_{j o t} \alpha_{j o t} & \leq 0 \text { for } j \in J, o \in O^{C B}, t \in T, \\
\alpha_{j o(t-1)}+\beta_{j o(t-1)}-\alpha_{j o t} & =0 \text { for } j \in J, o \in O^{C B}, t \in T, \\
\sum_{j \in J} \sum_{o \in O} b_{j o t}\left(\beta_{j o t}+\Lambda_{j o t}\right) & \leq B_{t} \text { for } t \in T .
\end{aligned}
$$

\subsection{Theoretical Complexity}

The theoretical complexity of the model is considered in terms of both modeled components. Regarding the resource allocation component, consider the decisions to mobilize and deploy a single resource from every response site. If the deployment time is considered to be a transportation cost, then minimizing this objective is a special case of the facility location problem - since we may need to build an infrastructure capability at the site - which is NP-hard. Regarding the oil spill response component, an argument similar to the complexity proof of total weighted tardiness (Pinedo, 2008) can be transformed into an argument for the problem of total weighted response time with follow-on tasks. Therefore, given that these problems are also NP-hard, the problem (e.g., consisting of both components) is also NP-hard. The IP model performs 
sufficiently to examine the problem of improving weighted oil spill response times in the Alaskan Arctic as a function of dynamic resource allocation and infrastructure investment decisions. However, additional work may be necessary to address the complexity of this problem when applied to other regions.

\section{Case Study: Arctic Oil Spill Response}

A case study was developed to address the case study questions (Section 2) and to test the model. The information that was utilized, from public sources and expert interviews, was vetted by oil spill response experts in order to develop test instances that encompass realistic aspects pertaining to oil spill response in the Arctic. This data set focused on the Alaskan Arctic which includes the Beaufort and Chukchi seas as well as the North Slope, i.e., the coastal region of Northern Alaska. Figure 3 illustrates the response sites and potential spill incidents considered in the case study; these sites and incidents are discussed in the following sections. Section 5.1 discusses Arctic oil spill response sites that comprise the response network. Section 5.2 discusses temporal aspects and their impact on operations in the region. Section 5.3 discusses the method developed to generate potential spill incidents. Section 5.4 discusses how the tasks and resources are determined for a specific spill incident. The Online Appendix provides more details surrounding the discussions in this section.
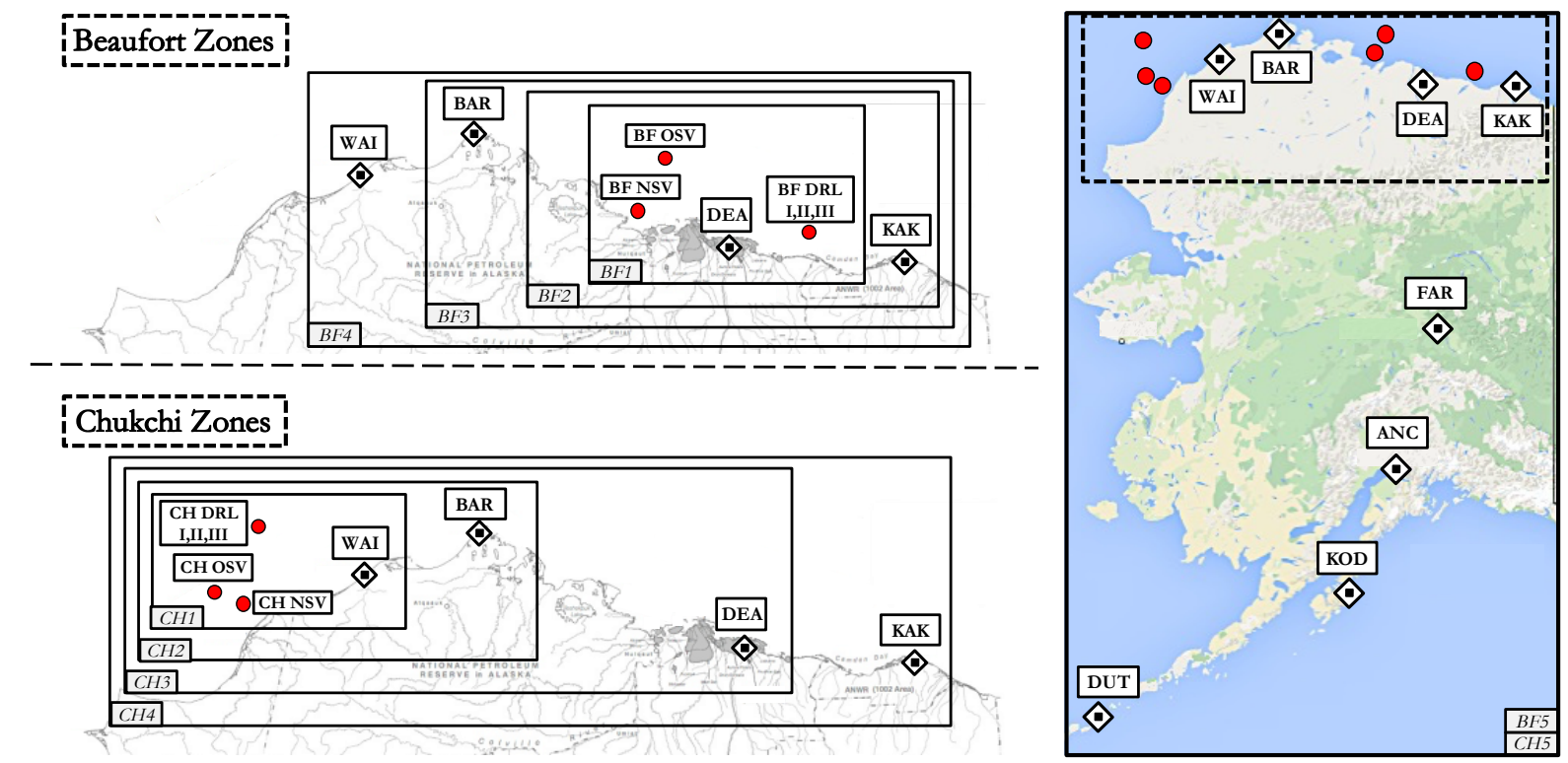

Figure 3: The two categories of response zones, labeled by increasing distance from the incident locations. Each response zone category is comprised of four zones on the North Slope (BF1-BF4, CH1-CH4) and one zone encompassing the entire state (BF5,CH5). Beaufort Sea incidents (upper left): Beaufort Drill Incident I - Beaufort Drill Incident III (e.g., BF DRL I,II,III), Beaufort Nearshore Vessel Incident (e.g., BF NSV) and Beaufort Offshore Vessel Incident (e.g., BF OSV). Chukchi Sea incidents (lower left): Chukchi Drill Incident I - Chukchi Drill Incident III (e.g., CH DRL I,II,III), Chukchi Nearshore Vessel Incident (e.g., CH NSV) and Chukchi Offshore Vessel Incident (e.g., CH OSV). 


\subsection{Response Sites}

Eight communities were deemed by domain experts to be suitable to act as response sites based on their available infrastructure, population, and location. These include four North Slope and Northwest Borough villages spread across the Beaufort and Chukchi energy exploration regions, each with at most 5,000 residents (e.g., Barrow, Deadhorse, Kaktovik, and Wainwright), in addition to four communities in central and southern Alaska (e.g., Anchorage, Dutch Harbor, Fairbanks, and Kodiak). Two sites on the North Slope were identified as primary response sites, capable of mobilizing resources directly to the incident locations, with one in the Beaufort region (e.g., Deadhorse) and one in the Chukchi region (e.g., Wainwright), as identified in current federally- and state-required oil spill response contingency plans (U.S. Department of the Interior, Bureau of Ocean Energy Management, 2011a b). The remaining six sites were identified as secondary response sites, where resources are first transported to a primary response site prior to mobilization. We can group the response sites into two types of response zones, Beaufort response zones and Chukchi response zones, as defined by the geographic proximity of each site to the incidents in the Beaufort Sea and Chukchi Sea, respectively. Analysis of response zones permits examination of response site criticality by examining how the timeliness of equipment arrival impacts decisions surrounding infrastructure investment, resource allocation, and resource deployment. Summary characteristics for the eight sites including the hub of Anchorage, a secondary response site in the south of Alaska through which resources arrive from other Oil Spill Response Organizations (OSRO's) within and outside the state, can be found in the Online Appendix. The offshore resources necessary for drill incidents are assumed to be deployed by oil companies and OSRO's, and these resources have negligible transit times to the drilling wells given that they are pre-staged locally (U.S. Department of the Interior, Bureau of Ocean Energy Management, 2011a|b). Additionally, these pre-staged resources are assumed to supply $50 \%$ of the offshore vessel incidents' requirements, given expert feedback that these resources cannot currently be sited in the Arctic.

\subsection{Temporal Aspects}

Response tactics for all oil spill incidents are considered during the short, 4-month period (June September) when temperature and ice conditions permit oil exploration, exploratory drilling, and support vessel navigation. Tactics are not considered during the 1-month periods (May, October) when significant ice is present in waterways due to changing seasons. Tactics for sustained drilling operations are also considered during the 6-month period (November - April) comprising winter seasons, given the ability for these operations to occur in the presence of solid ice. Spill response during these seasons requires different tactics compared with during summer seasons due to the presence of solid pack ice, and although the total weighted response time for an incident is impacted by the set of tasks required each season, seasonality does not necessarily impact spill location. Winter response tactics also require fewer types of resources, and in fewer numbers, than summer seasons (Alaska Clean Seas. 2012), and expert interviews suggested that infrastructure investments are impossible during winter time periods. Given these considerations, and that the functional form of the solutions for summer and winter seasons were found to be similar, the driver of 
the model's decisions is the improvement of summer time periods. Therefore, despite the model's ability to capture seasonality, only the results from summer time periods are presented in Section 7 , given that each winter season is utilized in order to prepare for the following summer season. Thus, while twenty resource allocation time periods were generated that represent these summer and winter seasons over the course of ten years, only trends regarding the ten summer seasons are considered in Section 7 . For each potential incident occurring in each of these seasons, 28 response time horizon periods were generated, representing six-hour periods over the course of one week.

\subsection{Generating Potential Spill Incidents}

The attributes of each spill incident determine the response tactics necessary based on the following descriptors: (i) incident source, such as vessel spillage or drill platform blowout; (ii) volume and type of product discharged; (iii) distance from shore; (iv) personnel safety considerations; and (v) environmental and geographical factors (Alaska Clean Seas, 2012). Three types of incident sources were selected, consistent with required federal and state oil spill response contingency plans, to occur in each sea: a drilling well blowout, a nearshore-, and an offshore-vessel incident (U.S. Department of the Interior, Bureau of Ocean Energy Management, 2011b a; Papp, 2013; National Academy of Sciences, 2014). The nearshore- and offshore vessel incidents were generated for the Beaufort and Chukchi Seas based on OSRO guidelines (United States Coast Guard, 2013), in order to examine the resource configurations necessary to support these independent of the drill incidents. Three different discharge volume levels, ordered from least to greatest, were modeled for incidents in the Beaufort Sea (e.g., Beaufort Drill Incident I - Beaufort Drill Incident III) and Chukchi Sea (e.g., Chukchi Drill Incident I - Chukchi Drill Incident III), as estimated from U.S. Department of the Interior, Bureau of Ocean Energy Management (2011a b). One discharge volume level was modeled for nearshore- and offshore-vessel incidents in the Beaufort Sea (e.g., Beaufort Nearshore Vessel Incident and Beaufort Offshore Vessel Incident, respectively) and Chukchi Sea (e.g., Chukchi Nearshore Vessel Incident and Chukchi Offshore Vessel Incident, respectively), as estimated from United States Coast Guard (2013).

\subsection{Determining Tasks and Resources for a Specific Spill Incident}

Six task strategies were considered, which grouped the modeled tasks by function: three strategies pertained to recovering the spillage volume (e.g., mechanical recovery, in-situ burning, and dispersant application); and three pertained to non-recovery operations (e.g., human safety, logistics, and spill trajectory tracking) (Alaska Clean Seas, 2012). Domain experts identified the task weights based on these functions, and tasks were considered independent of each other; weights for disposal and logistics

were half the weights for all other tasks. Additionally, experts noted that incidents can occur that only require spill tracking, and none of the other five strategies would be utilized. The analysis presented in Section 7 excludes these types of incidents, and instead is focused on response efforts which also require a combination of the other task strategies. 
The initial and follow-on task lists and associated resource requirements were generated for each of the eight task pairs as necessary to address the strategies for each incident. For recovery strategies, tasks representing both containment and recovery (e.g., mechanical recovery strategy), in-situ burning, and dispersant application were considered. Please see the Online Appendix for details on how the resource types and requirements were calculated for these tasks. For all other strategies, disposal, logistics, safety, and tracking tasks were considered. The safety task (e.g., $f$ ) takes priority over all tasks, except logistics and tracking, given the nature of these tasks and their ability to be completed without providing further risk to human safety.

Fourteen resource types were modeled, which represent generic forms of the most significant equipment required for the modeled tasks: Small Aircraft; Large Aircraft; Offshore Boom; Near Shore Boom; In-Situ Burning Equipment; Dispersant; Mobile Command Facility; Near Shore Vessel; Offshore Vessel; Tank Vessel; Storage Bladder; Offshore Skimming Vessel; Skimmer System; and Ground Vehicles. These resources were dependent on the availability of specific infrastructure design options; for instance, a near shore vessel requires gravel pad space for storage on land, a refueling source, and a small boat launch for deployment at an incident site.

\section{Computational Analysis: Test Instances and Solution Times}

The problem is analyzed for computational difficulty in terms of the test instances derived from the case study (Section 5), and in terms of additional instances developed to reveal further insight and trends in problem difficulty. All instances were tested under CPLEX 12.6 on an 8-core computer with 64 GB of RAM, and these were run until the optimality gaps were less than $4.00 \%$. The goal is to examine and compare solutions of sufficient quality given variation in the parameter(s) of interest as indicated by the (relatively) small optimality gaps. Table 4 provides summary characteristics and computational runtimes for the test instances.

Certain instances are defined by varying the budget for resource allocation decisions $\left(A_{t}\right)$. These budget instances are defined by the percentage difference between the budget level required to maintain the initial stockpile, and the minimum budget level required to achieve the best possible stockpile. For instance, the $0.00 \%$ level permits no resource allocation decisions due to stockpile maintenance costs, whereas $25.00 \%$ permits some of these decisions. The budget for infrastructure investment decisions $\left(B_{t}\right)$ is fixed for these instances. Instances feature a resource allocation time horizon length of $T=20$ unless otherwise indicated. The test instances are represented as follows:

(i) Base network resource allocation budget instances: $A_{1}, A_{2}, \ldots, A_{7}$, defined by varying the resource allocation budget $A_{t}$ for the base response network described in Section 5.1. These budget instances are examined so that the functional form of the solutions and patterns pertaining to resource stockpile configuration can be considered.

(ii) Enhanced network resource allocation budget instances: $D_{1}, D_{2}, \ldots, D_{7}$, defined by varying the resource allocation budget $A_{t}$ for the base response network enhanced by the inclusion of four 
capability-limited DEW Line sites in the Chukchi Sea region. These budget instances examine trends in problem difficulty as the size of the response network grows and provide insights into the impact on response capabilities with a larger network. Additional discussion of these sites can be found in the Online Appendix.

(iii) Semi-enhanced network instances: $D_{2}^{*}, D_{3}^{*}, \ldots, D_{7}^{*}$, defined by varying the resource allocation budget $A_{t}$ for the response network enhanced by the inclusion of two capability-limited DEW Line sites in the Chukchi Sea. These instances were developed outside of the case study in order to examine trends in problem difficulty as the size of the response network grows.

(iv) Infrastructure investment budget instances: $B_{\min }$ and $B_{\max }$, defined by reduced and increased values of budget $B_{t}$, respectively. These budget instances are examined so that the impacts from restricting infrastructure investment decisions can be explored. Two levels of the infrastructure budget are considered: the $8 \%$ level permitted stockpiling only land-based resources; and an unconstrained budget. The remaining instances were also tested with an unconstrained infrastructure investment budget.

(v) Delayed task completion instances: $F_{\min }$ and $F_{\max }$, defined by reduced and increased completion times of the safety task $f$, respectively. These task completion instances are examined so that the impacts from delayed safety task completion time can be explored.

(vi) Resource deployment instances: $u_{\min }$ and $u_{\max }$, defined by reduced and increased values of the site-based resource mobilization limiter $u_{j}$. These resource deployment instances are examined so that the impacts from limiting resource mobilization from the response sites can be explored. $u_{\max }$ includes the most unconstrained problem conditions for this study.

(vii) Extended time horizon instances: $A_{01}^{*}, \ldots, A_{04}^{*}$, defined by varying the resource allocation budget $A_{t}$ for the base response network under an extended time horizon $(T=30)$. These instances were developed outside of the case study in order to examine trends in problem difficulty as the number of time periods grows. Note that the budgets are significantly reduced in order to ensure that resource allocation decisions will be made over the time from periods 20 to 30 .

As seen in Table 4 instances of highly-constrained budget levels, combined with an extended time horizon length (e.g., $A_{01}^{*}, \ldots, A_{04}^{*}$ ), demonstrate significant increases in problem difficulty. Increasing the network's size also increases problem difficulty, and it is noted that this difficulty increases as more sites are introduced to the network, as observed by comparing runtimes for the base network instances with the semi-enhanced and enhanced network instances (e.g., instances $D_{x}$ versus $D_{x}^{*}$ ). However, domain experts observed that, in the context of the case study setting (Section 5), the practical need to solve the problem with an increased network size, and for 30 or more time periods, is reduced. Although run times may approach 24 hours, these are strategic, long-term decisions that do not require real-time decision support. Therefore, problems of $T=30$ time periods could be examined, but the size of the problem that is solvable without customized solution approaches is more obvious in this analysis. Therefore, these runtimes are sufficient for the purposes of this analysis, and the need exists for future work to explore methods to promote solvability for 
case studies representing larger data sets.

Problem difficulty is reduced for the most- and least-constraining values of the resource allocation budget (e.g., $A_{1}, D_{1}$ and $A_{7}, D_{7}$ ) and infrastructure investment budget (e.g., $B_{\min }$ and $B_{\max }$ ). These times also demonstrate a gradual rise and fall in difficulty around certain spikes (e.g., $A_{4}, D_{5}^{*}$, and $D_{3}$ ). Increasing the time horizon length (e.g., instances $A_{x}$ versus $A_{x}^{*}$ ) does not necessarily follow this trend, but in general, this aspect of the problem does not significantly increase the problem's difficulty, given the tendency to reach a steady-state solution as discussed in Section 7.1. Relieving sources of bottlenecks (e.g., $u_{\min }$ ) and task completion delays (e.g., $F_{\min }$ ) decreases problem difficulty. Therefore, the problem's difficulty is impacted most by the budget level and network's size.

\begin{tabular}{|c|c|c|c|c|c|}
\hline Instance & $\%$ above $\min \left(A_{t}\right)$ & Obj & $\mathrm{CT} \%$ & RT (s) & Gap $\%$ \\
\hline \multicolumn{6}{|c|}{$T=20$} \\
\hline$A_{1}$ & $0.00 \%$ & 18630 & $17.50 \%$ & 256 & $0.00 \%$ \\
\hline$A_{2}$ & $0.50 \%$ & 8751 & $5.75 \%$ & 11576.54 & $3.96 \%$ \\
\hline$A_{3}$ & $1.00 \%$ & 8685 & $5.75 \%$ & 12591.70 & $3.95 \%$ \\
\hline$A_{4}$ & $5.00 \%$ & 8388 & $4.88 \%$ & 24491.82 & $3.95 \%$ \\
\hline$A_{5}$ & $10.00 \%$ & 8195 & $4.25 \%$ & 16995.02 & $4.01 \%$ \\
\hline$A_{6}$ & $25.00 \%$ & 7955 & $4.38 \%$ & 19813.11 & $3.99 \%$ \\
\hline$A_{7}$ & $1000.00 \%$ & 7750 & $4.25 \%$ & 5730.91 & $3.80 \%$ \\
\hline$D_{1}$ & $0.00 \%$ & 18630 & $17.50 \%$ & 256 & $0.00 \%$ \\
\hline$D_{2}$ & $0.50 \%$ & 8584 & $5.75 \%$ & 18577.51 & $3.98 \%$ \\
\hline$D_{3}$ & $1.00 \%$ & 8539 & $5.63 \%$ & 84947.76 & $3.88 \%$ \\
\hline$D_{4}$ & $5.00 \%$ & 8246 & $5.50 \%$ & 73496.41 & $3.96 \%$ \\
\hline$D_{5}$ & $10.00 \%$ & 8048 & $5.00 \%$ & 49942.34 & $3.96 \%$ \\
\hline$D_{6}$ & $25.00 \%$ & 7828 & $4.88 \%$ & 56060.31 & $4.00 \%$ \\
\hline$D_{7}$ & $1000.00 \%$ & 7722 & $4.50 \%$ & 50878.48 & $4.01 \%$ \\
\hline$D_{2}^{*}$ & $0.50 \%$ & 8598 & $5.75 \%$ & 14200.79 & $3.64 \%$ \\
\hline$D_{3}^{*}$ & $1.00 \%$ & 8550 & $5.63 \%$ & 20773.80 & $4.00 \%$ \\
\hline$D_{4}^{*}$ & $5.00 \%$ & 8254 & $5.50 \%$ & 24506.75 & $3.99 \%$ \\
\hline$D_{5}^{*}$ & $10.00 \%$ & 8027 & $5.00 \%$ & 41911.18 & $3.72 \%$ \\
\hline$D_{6}^{*}$ & $25.00 \%$ & 7795 & $4.88 \%$ & 14045.59 & $3.90 \%$ \\
\hline$D_{7}^{*}$ & $1000.00 \%$ & 7758 & $4.50 \%$ & 18160.41 & $4.06 \%$ \\
\hline$B_{\min }$ & $1000.00 \%$ & 8667 & $8.75 \%$ & 1061.40 & $0.03 \%$ \\
\hline$u_{\min } / F_{\min } / B_{\max }$ & $1000.00 \%$ & 7737 & $4.25 \%$ & 7200.00 & $3.53 \%$ \\
\hline$F_{\max }$ & $1000.00 \%$ & 11276 & $5.75 \%$ & 14531.81 & $0.23 \%$ \\
\hline$u_{\max }$ & $1000.00 \%$ & 6829 & $2.38 \%$ & 267.36 & $0.00 \%$ \\
\hline \multicolumn{6}{|c|}{$T=30$} \\
\hline$A_{1}^{*}$ & $0.00 \%$ & 27945 & $17.50 \%$ & 256 & $0.00 \%$ \\
\hline$A_{01}^{*}$ & $0.10 \%$ & 12618 & $6.00 \%$ & 32338.83 & $4.00 \%$ \\
\hline$A_{02}^{*}$ & $0.20 \%$ & 12408 & $5.75 \%$ & 32852.13 & $3.77 \%$ \\
\hline$A_{03}^{*}$ & $0.30 \%$ & 12249 & $5.75 \%$ & 49266.89 & $3.94 \%$ \\
\hline$A_{04}^{*}$ & $0.40 \%$ & 12184 & $5.75 \%$ & 45163.66 & $4.00 \%$ \\
\hline
\end{tabular}

Table 4: Solution characteristics of the test instances. Solution characteristics include: (a) \% above $\min \left(A_{t}\right)$ represents variations to the resource allocation budget, (b) Obj represents the objective function value, (c) CT\% represents the average percentage of follow-on tasks completed, (d) RT (s) represents the run time in seconds, and (e) Gap\% represents the percentage optimality gap reported.

\section{Computational Analysis: Addressing the Case Study Questions}

The case study results address the Section 2 case study questions through analysis of the test instances introduced in Section 6. Due to the heightened impact of decisions made during summer seasons (see Section 5 and the Online Appendix), the analysis only considers summer time periods. However, overall trends are indicative of the response in winter time periods. 
Results are discussed in the following sections. Section 7.1 analyzes the base network budget instances (e.g., instances $A_{1}-A_{7}$ ) to examine how the resource allocation budget impacts weighted response times. Section 7.2 further analyzes the base network budget instances to examine the stockpile configurations in relation to the resource allocation budget. Section 7.3 examines the infrastructure investments made in order to support the stockpile configuration decisions in Section 7.2. Section 7.4 explores impacts on the base network budget instances due to: resource deployment bottlenecks (e.g., instances $u_{\text {min }}, u_{\text {max }}$ ); delayed safety task completion time $\left(F_{\min }, F_{\max }\right)$; and the tasks completed given the decisions made by the base network budget instances in previous sections. Finally, Section 7.5 examines the impacts resulting from enhancing the response network with the addition of four limited-capability sites (e.g., instances $D_{1}-D_{7}$ ).

\subsection{Budget vs. Weighted Response Times}

CS1: What are the impacts on response times of budgetary limitations? Budgetary limitations impact the level to which response times are reduced, and the number of time periods required to attain the best response. Figure 4 shows that early budget increases-of up to $10 \%$-markedly impact oil spill response time. Indeed, a $53.03 \%$ improvement in the total weighted response time for the $0 \%$ budget level $\left(A_{1}\right)$ is attained by budget instance $A_{2}$, or $0.5 \%$ above the level to maintain the initial stockpile. A similar improvement is also observed for the solution to the reduced-infrastructure budget instance, $B_{\text {min }}$, compared with instance $A_{1}(53.48 \%)$. The figure also demonstrates that significant improvements to each incident's response times are attained in Summer 3 (S3) and S5 at each budget level above $A_{1}$. Taken together, these observations indicate that a significant improvement to oil spill response times might only require relatively small stockpile and infrastructure investments.
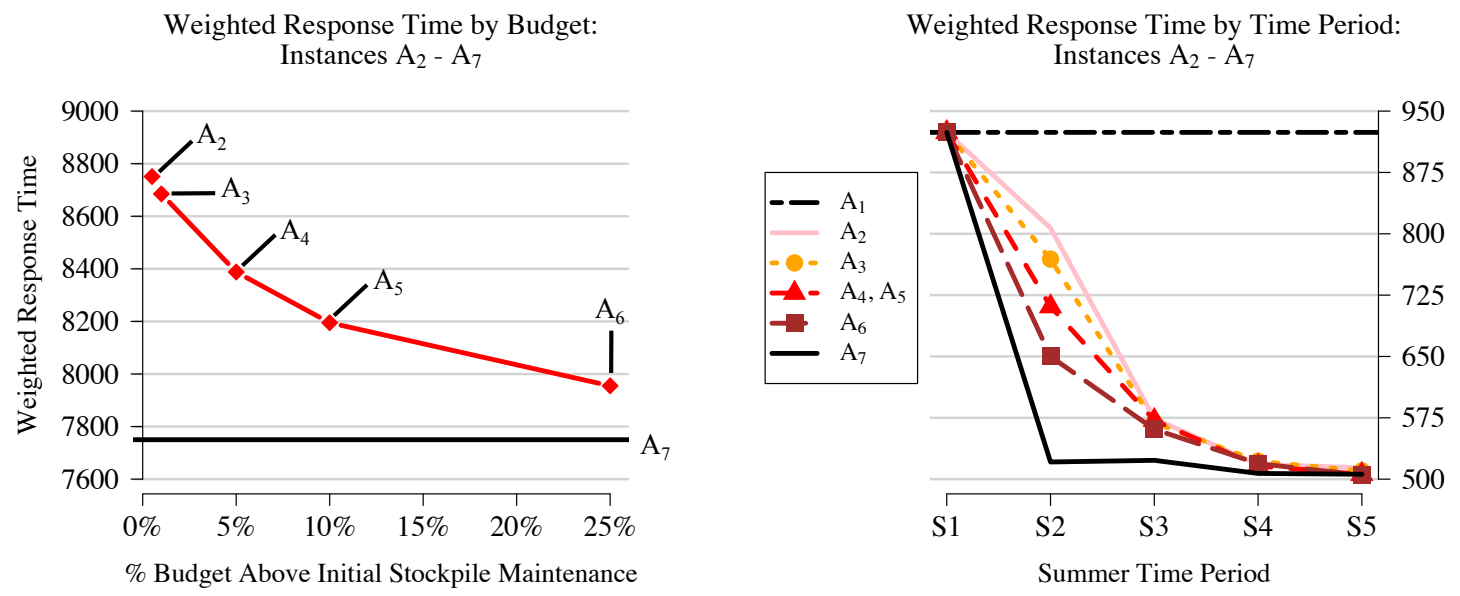

Figure 4: Left: Weighted response times by non-zero budget level for the original network instances (e.g., $A_{2}-A_{6}$ ). The minimum value reported for the uncapacitated instance is displayed for reference as the best possible solution. Budget instance $A_{1}$ (solution: 18630) is omitted for clarity. Right: Weighted response times for the first five Summer time periods for the original network instances. Note that $5 \%$ and $10 \%$ solutions overlap in this figure despite differences in their solutions. 
Figure 4 demonstrates that improvements to the budget reduce the number of time periods required until each instance can reach a best possible response (e.g., 514), which is represented by the best summer response time to the uncapacitated budget instance $A_{7}$. All budget levels approach this best possible solution with a response time of under 575 by Summer S3 from a starting point of 924, and each instance attains the best solution by S5. However, improved response times are largest for earlier rounds of investment, and budget levels above $25 \%$ provide less returns on investment. Therefore, diminished returns on investment are observable, in terms of improved weighted response times, as the resource allocation budget is increased. Decision-makers should take into consideration how diminishing returns on investments to improve oil spill response times can impact long-term plans to improve an Arctic response network.

\subsection{Stockpile Investments}

CS2: How does geographic position within the response network influence the scale and scope of a stockpile? The impact of response site geographic position on the solution depends on the resource allocation budget, and, potentially, whether the site is centrally located. Table 5 demonstrates that the total number of resources stockpiled at each site can fluctuate over time at each budget level, eventually resulting in the amounts necessary to sustain the steady state solution (e.g., by Summer S5). Within these totals, certain resource types are stockpiled particularly early, such as boom and offshore vessels, which reflects their importance early in the response time horizon. Stockpile trends at Wainwright, the remote Chukchi primary response site, demonstrate this trend for sea- and land-based resources and vessel-based recovery equipment, necessary for most recovery task strategies (Section 5.4. These trends indicate that Anchorage, Dutch Harbor, and Deadhorse supply more of these resources to Wainwright at lower budget levels than at higher levels, in order to improve the early stages of a response in that region. Fairbanks and Barrow stock less equipment early in the time horizon, including boom, skimmers, and vehicles, but these amounts increase with the budget. Stockpiling decisions thus split resource amounts between response sites at different budget levels, addressing changing needs for resources over the response timeline. Taken in line with the results from Section 7.1. decision-makers can see the impact and importance of early budget increases on response time, and on the need for budget increases to improve stockpile configurations

at different (remote) response sites earlier in the response. These results give insight into the site- and location-specific impacts of budget allocations over time.

Centrality within a response network refers to the degree to which a response site is positioned equidistant to all potential spill incident locations. Response sites that are more central have a maximum transit time to any one incident location that is similar to the average transit time to all incident locations, a consideration for decision-makers planning a response for multiple potential incidents. Stockpiling decisions at Barrow can provide insight into the significance of site centrality within the network.

The stockpile at Barrow, positioned between the primary response sites in the Beaufort region (e.g., Deadhorse) and Chukchi region (e.g., Wainwright), is improved early in the time horizon but receives 


\begin{tabular}{|c|c|c|c|c|c|c|c|c|c|c|c|c|c|}
\hline & & \multicolumn{4}{|c|}{$A_{2}$} & \multicolumn{4}{|c|}{$A_{3}$} & \multicolumn{4}{|c|}{$A_{4}$} \\
\hline Site & Zone $_{B F}$ & $S 2$ & S3 & S4 & S5 & $S 2$ & S3 & S4 & S5 & $S 2$ & S3 & $S 4$ & S5 \\
\hline Anchorage & 5 & 592 & 494 & 414 & 607 & 594 & 494 & 730 & 608 & 556 & 520 & 759 & 611 \\
\hline Dutch Harbor & 5 & 158 & 86 & 45 & 2 & 158 & 101 & 54 & 54 & 101 & 86 & 15 & 166 \\
\hline Kodiak & 5 & 89 & 74 & 77 & 57 & 87 & 75 & 40 & 99 & 85 & 53 & 3 & 186 \\
\hline Deadhorse & 1 & 562 & 581 & 734 & 529 & 571 & 579 & 359 & 319 & 584 & 587 & 469 & 284 \\
\hline Fairbanks & 5 & 0 & 67 & 8 & 109 & 0 & 59 & 185 & 247 & 0 & 98 & 20 & 38 \\
\hline Wainwright & 4 & 15 & 143 & 157 & 212 & 50 & 41 & 124 & 186 & 122 & 109 & 209 & 207 \\
\hline Barrow & 3 & 22 & 56 & 95 & 80 & 11 & 141 & 67 & 95 & 11 & 53 & 69 & 90 \\
\hline \multirow[t]{2}{*}{ Kaktovik } & 2 & 0 & 8 & 6 & 50 & 0 & 3 & 0 & 25 & 2 & 27 & 0 & 0 \\
\hline & & \multicolumn{4}{|c|}{$A_{5}$} & \multicolumn{4}{|c|}{$\overline{A_{6}}$} & \multicolumn{4}{|c|}{$\overline{A_{7}}$} \\
\hline Site & Zone $_{\mathrm{CH}}$ & $S 2$ & S3 & $S 4$ & S5 & S2 & $S 3$ & $S 4$ & S5 & $S 2$ & $S 3$ & $S 4$ & $S 5$ \\
\hline Anchorage & 5 & 531 & 512 & 718 & 680 & 520 & 518 & 700 & 719 & 499 & 497 & 418 & 596 \\
\hline Dutch Harbor & 5 & 101 & 68 & 38 & 1 & 97 & 84 & 74 & 64 & 132 & 52 & 144 & 198 \\
\hline Kodiak & 5 & 88 & 99 & 98 & 106 & 83 & 66 & 148 & 142 & 83 & 36 & 174 & 23 \\
\hline Deadhorse & 3 & 577 & 593 & 409 & 326 & 559 & 535 & 309 & 314 & 262 & 318 & 288 & 288 \\
\hline Fairbanks & 5 & 1 & 112 & 104 & 40 & 88 & 137 & 119 & 128 & 41 & 54 & 151 & 161 \\
\hline Wainwright & 1 & 118 & 111 & 127 & 257 & 91 & 113 & 165 & 195 & 205 & 416 & 282 & 238 \\
\hline Barrow & 2 & 19 & 48 & 65 & 85 & 17 & 65 & 78 & 193 & 318 & 162 & 128 & 115 \\
\hline Kaktovik & 4 & 6 & 0 & 0 & 97 & 31 & 55 & 84 & 0 & 71 & 85 & 121 & 87 \\
\hline
\end{tabular}

Table 5: Resource stockpiles at each site in the Beaufort $\left(\right.$ Zone $\left._{B F}\right)$ and Chukchi $\left(Z_{0 n e} e_{C H}\right)$ zones, averaged across the Summer time periods featuring stockpile improvements up to the steady state solution (e.g., S2 - S5). Values displayed are for the non-zero budget instances for the original network (e.g., $A_{2}-A_{7}$ ).

smaller stockpile increases compared to Wainwright, especially at the lowest budget levels. Given that the stockpile at Deadhorse is typically reduced, due to the significant oil spill response capability of that site, the improvements at Barrow suggest that its stockpile is increased in order to serve the Chukchi region. These observations demonstrate that improving Barrow's stockpile, despite its central location between the Chukchi and Beaufort primary response sites, is not as important as improving Wainwright's stockpile, because of Wainwright's role as the Chukchi region primary response site and the need to improve incident response in that region. Decision-makers now have visibility of the timing and tradeoffs between and among response sites over the course of the response time horizon.

The observations in this section indicate that centrality in a response network, assumed to be a desirable quality, has a temporal characteristic: early in the response, for critical response tasks, centrality of a response site plays a less-important role in mobilizing the pre-staged resources that are available immediately. Once response supply chains are energized, centrality plays a more important role in improving response times.

CS3: What is the optimal stockpile improvement policy? The optimal stockpile improvement policy is impacted by the demands of each potential spill incident as defined by the case study setting, and by the extent to which a site is utilized. The results indicate that response zone 5, including southern Alaska and sites outside the network, will likely provide a significant amount of resources (e.g., $\geq 40 \%$ ) for incidents of catastrophic volume, as illustrated in Figure 5. Figure 5highlights this for Chukchi Sea incidents, given that Deadhorse also provides significant support in that region. This observation also holds for the case of an unlimited budget (e.g., $A_{7}$ ), which supersedes the intuitive assumption that the closest response sites might eventually stockpile to the point of self-reliance, i.e., Arctic oil spill response might always rely on response 
sites in the south, such as Anchorage, Kodiak, and Dutch Harbor, due to the limitations of the North Slope sites. This phenomena occurs because of maximally utilizing a North Slope site, which can occur due to the site's mobilization capacity (Section 4.2), or how many resources it can prepare for transport to the incident location per response time period $s$. For example, if the capacity for Wainwright is sufficiently small, then a deployment bottleneck could result at Wainwright and it would be more beneficial to relieve this bottleneck by mobilizing resources from another site. Therefore, this mobilization capacity prevents all resources from being sited at Wainwright (even with an unlimited budget), which reduces the need for infrastructure investments at the site. Under these conditions, Wainwright is considered 'maximally utilized,' and its stockpile would be similar across budget levels due to the bottleneck that is formed by its mobilization capacity.

Chukchi Drill Incident III

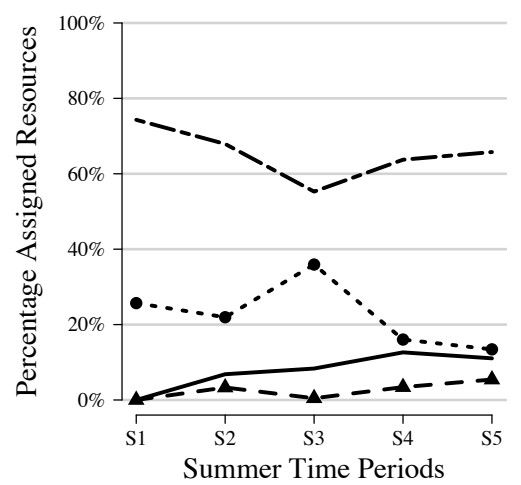

Chukchi Offshore Vessel Incident

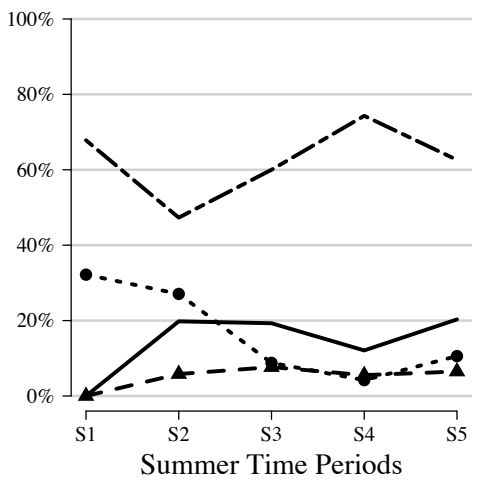

Chukchi Nearshore Vessel Incident

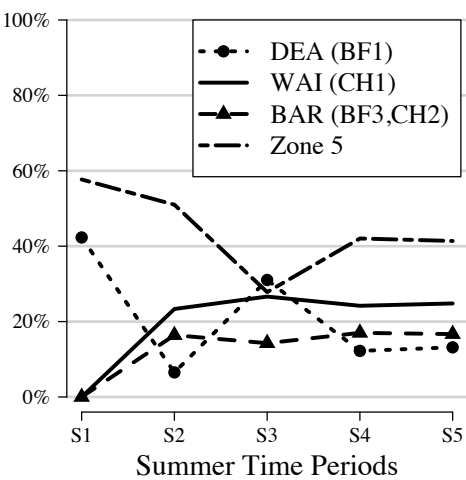

Figure 5: The percentage of resources that were mobilized for the Chukchi region incidents from key response sites during the summer time periods until the steady state solution (e.g., up to Summer $S 5)$ of the unlimited budget instance (e.g., $\left.A_{7}\right)$. The response sites (and associated response zones) include: Deadhorse (DEA), Wainwright (WAI), and Barrow (BAR). Kaktovik (e.g., response zones $\mathrm{BF}_{2}, \mathrm{CH}_{4}$ ) is omitted due to the negligible improvement afforded by the inclusion of that site.

The stockpiling trends in Table 5, considered with the trends to assign resources from response sites to Chukchi Sea incidents (e.g., Figure 5), indicate that maximal utilization impacts the primary sites (e.g., Wainwright in the Chukchi region, and Deadhorse in the Beaufort region), and the secondary site Barrow, but not Kaktovik. In the table, the trend is observed to 'level off' the stockpiles in Wainwright and Barrow once the steady state solution is reached (e.g., by Summer S5). In the figure, this trend is represented by the flattened resource assignment levels as the budget is increased. Figure 5 demonstrates that the Chukchi region exhibits greater reliance on distant support, and that Deadhorse can play a significant role in the response to an incident in this region. Barrow also plays an important role in the response for the Chukchi region; for example, Barrow assigns almost the same amount of resources to the Chukchi Nearshore Vessel Incident as Wainwright. These observations indicate that, although maximal utilization is a significant factor for Arctic response sites, its effects could be reduced by stockpiling resources at Barrow and Deadhorse in order to support Wainwright. This reveals a type of coordination between the response 
sites, determined by the role each site plays in mobilizing resources for each specific incident, which should be examined by decision-makers considering mobilization-limited response sites in the Arctic and similar regions. Regardless, the observed maximal utilization reveals that stockpiling every type of resource - and improving all associated infrastructures - at the response sites closest to the potential incidents of greatest concern is not necessarily the best policy in the Arctic.

\subsection{Infrastructure Investments}

CS4: What is the optimal infrastructure investment policy? The optimal infrastructure investment policy is impacted by budget level, and there exists a trend to the infrastructure investments made at each response site for resource allocation budget levels below $A_{7}$. Table 6 displays the earliest Summer time periods selected to invest in both infrastructure classes, the capability class $\left(C B_{x}\right)$ and the capacity class $\left(C P_{x}\right)$. The trend is observed to improve Wainwright earlier and to a greater degree than Barrow.

\begin{tabular}{|c|cccc|ccccc|cccc|ccc|}
\cline { 2 - 15 } \multicolumn{1}{c|}{} & \multicolumn{10}{c|}{$A_{2}$} & \multicolumn{1}{c|}{$A_{3}$} & \multicolumn{4}{c|}{$A_{4}$} \\
\hline Site & $C B_{1}$ & $C B_{2}$ & $C B_{3}$ & $C B_{4}$ & $C B_{1}$ & $C B_{2}$ & $C B_{3}$ & $C B_{4}$ & $C B_{1}$ & $C B_{2}$ & $C B_{3}$ & $C B_{4}$ & $C B_{1}$ & $C B_{2}$ & $C B_{3}$ & $C B_{4}$ \\
\hline Wainwright & $\mathrm{S} 1$ & $\mathrm{~S} 2$ & $\mathrm{~S} 1$ & $\mathrm{~S} 3$ & $\mathrm{~S} 1$ & $\mathrm{~S} 2$ & $\mathrm{~S} 1$ & $\mathrm{~S} 2$ & $\mathrm{~S} 2$ & $\mathrm{~S} 1$ & $\mathrm{~S} 1$ & $\mathrm{~S} 3$ & $\mathrm{~S} 1$ & $\mathrm{~S} 1$ & $\mathrm{~S} 1$ & $\mathrm{~S} 1$ \\
Barrow & $\mathrm{S} 3$ & $\mathrm{~S} 6+$ & $\mathrm{S} 1$ & $\mathrm{~S} 3$ & $\mathrm{~S} 4$ & $\mathrm{~S} 3$ & $\mathrm{~S} 1$ & $\mathrm{~S} 3$ & $\mathrm{~S} 3$ & $\mathrm{~S} 5$ & $\mathrm{~S} 2$ & $\mathrm{~S} 2$ & $\mathrm{~S} 1$ & $\mathrm{~S} 2$ & $\mathrm{~S} 1$ & $\mathrm{~S} 1$ \\
Kaktovik & $\mathrm{S} 6+$ & $\mathrm{S} 6+$ & $\mathrm{S} 6+$ & $\mathrm{S} 6+$ & $\mathrm{S} 6+$ & $\mathrm{S} 6+$ & $\mathrm{S} 6+$ & $\mathrm{S} 6+$ & $\mathrm{S} 6+$ & $\mathrm{S} 6+$ & $\mathrm{S} 6+$ & $\mathrm{S} 6+$ & $\mathrm{S} 2$ & $\mathrm{~S} 1$ & $\mathrm{~S} 1$ & $\mathrm{~S} 1$ \\
\hline Site & $C P_{1}$ & $C P_{2}$ & $C P_{3}$ & $C P_{4}$ & $C P_{1}$ & $C P_{2}$ & $C P_{3}$ & $C P_{4}$ & $C P_{1}$ & $C P_{2}$ & $C P_{3}$ & $C P_{4}$ & $C P_{1}$ & $C P_{2}$ & $C P_{3}$ & $C P_{4}$ \\
\hline Wainwright & $\mathrm{S} 1$ & $\mathrm{~S} 1$ & $\mathrm{~S} 6+$ & $\mathrm{S} 6+$ & $\mathrm{S} 1$ & $\mathrm{~S} 1$ & $\mathrm{~S} 6+$ & $\mathrm{S} 6+$ & $\mathrm{S} 1$ & $\mathrm{~S} 2$ & $\mathrm{~S} 6+$ & $\mathrm{S} 6+$ & $\mathrm{S} 1$ & $\mathrm{~S} 1$ & $\mathrm{~S} 6+$ & $\mathrm{S} 1$ \\
Barrow & $\mathrm{S} 2$ & $\mathrm{~S} 2$ & $\mathrm{~S} 6+$ & $\mathrm{S} 6+$ & $\mathrm{S} 1$ & $\mathrm{~S} 3$ & $\mathrm{~S} 6+$ & $\mathrm{S} 6+$ & $\mathrm{S} 1$ & $\mathrm{~S} 2$ & $\mathrm{~S} 6+$ & $\mathrm{S} 6+$ & $\mathrm{S} 1$ & $\mathrm{~S} 1$ & $\mathrm{~S} 6+$ & $\mathrm{S} 6+$ \\
Kaktovik & $\mathrm{S} 3$ & $\mathrm{~S} 6+$ & $\mathrm{S} 6+$ & $\mathrm{S} 6+$ & $\mathrm{S} 2$ & $\mathrm{~S} 6+$ & $\mathrm{S} 6+$ & $\mathrm{S} 6+$ & $\mathrm{S} 1$ & $\mathrm{~S} 6+$ & $\mathrm{S} 6+$ & $\mathrm{S} 6+$ & $\mathrm{S} 1$ & $\mathrm{~S} 1$ & $\mathrm{~S} 6+$ & $\mathrm{S} 6+$ \\
\hline
\end{tabular}

Table 6: Summer time periods of the first infrastructure investments (e.g., S1 - S5) for response sites initially lacking infrastructure in the Arctic, by class: capability $\left(C B_{x}\right)$, and capacity $\left(C P_{x}\right)$. Values shown are for budget instances $A_{2}-A_{4}$ and $A_{7}$ for emphasis. Time periods occurring after the steady state solution has been attained (e.g., Summer S6 and beyond) are represented by "S6+".

Wainwright improves nearshore-vessel siting capability and refueling capability (e.g., $\left.C B_{1}, C B_{3}\right)$ at lower budget levels, and improves offshore-vessel siting capability (e.g., $C B_{2}$ ) at higher budget levels. At budget levels below $A_{7}$, Barrow improves more affordable and more general capacity options, such as conex containers (e.g., $\left.C P_{1}\right)$ and gravel pads (e.g., $\left.C P_{2}\right)$, along with the refueling capability option $\left(C B_{1}\right)$. These investments in more affordable infrastructure options confirm the earlier claim that relatively modest budget investments can significantly improve weighted response times (Section 7.1). Thus, infrastructure investments in Barrow are focused on stockpiling resources that serve supporting roles for Wainwright and the incidents in the Chukchi region, regardless of budget level. Combined with the results from the previous section, these observations reveal the coordination strategy that develops sites in a specific order, which ultimately promotes each site's role within a response effort. Analysis of the infrastructure budget instances (e.g., $B_{\min }, B_{\max }$ ) indicates that improving sites located toward the center of the network (e.g., sites Fairbanks, Barrow) can be beneficial when the sites closest to the incidents are mobilization limited. These central sites can improve their infrastructures quickly and operate as smaller stockpile hubs when this budget is unconstrained, which demonstrates that coordination between response sites is beneficial at any infrastructure budget level. 


\subsection{Task Schedules}

CS5: How do bottlenecks and delayed resource deployments inform the solution? Sources of bottlenecks, caused by the delayed completion of the safety task (e.g., $F_{\min }, F_{\max }$ ), and the resource mobilization capacity (e.g., $\left.u_{\min }, u_{\max }\right)$, present factors for decision-makers to consider prior to making infrastructure investment and resource stockpiling decisions.

Delayed safety task completion results in a non-intuitive infrastructure investment pattern, which is similar to that of the best possible solution in terms of prioritizing improvement for less-critical sites (e.g., Kaktovik, Fairbanks, and Dutch Harbor). In this case, the lag associated with delayed task completions "pushes" the primary sites out of their response zones (e.g., zones $B F_{1}, C H_{1}$ ), and into the more distant zones instead, negating the benefit from stockpiling where the resource transit times are the least. Therefore, if the safety task is delayed, then improvements to the response sites closest to the incidents might not be worthwhile, given that resources could arrive from farther away - and thus at reduced infrastructure expense - and be ready for deployment immediately after the safety task. Decision-makers considering infrastructure investments for Arctic response sites should first weigh the investment costs against the potential for factors to arise which could cause significant delays to the response, resulting in reduced returns on these investments. Visibility of the tradeoffs between investment costs and response delay costs are new decision support capabilities for Arctic oil spill response decision-makers.

Analysis of the resource deployment instances support these observations, indicating that even the best response relies on infrastructure improved at sites positioned farther away from the incidents in later time periods. If each site's mobilization capacity is not a limiting factor, then significantly reduced response times are attainable (Table 4), and decision-makers should examine potential causes that could reduce resource mobilization capacity at current and future response sites.

CS6: What are optimal task completion policies? The stockpile and infrastructure investment decisions, discussed previously, impact the priority to complete each task strategy and the type of response site selected for each task. Six task strategies are considered (Section 5): the safety task, mechanical recovery, in-situ burning, dispersants application, logistics, and spill tracking.

Two of the spillage volume recovery strategies, mechanical recovery and in-situ burning, are responsible for addressing the majority of the spillage volume (97\%). Completion of these types of tasks is prioritized at the primary response sites (e.g., Wainwright and Deadhorse), regardless of resource mobilization capacity. Barrow's role as a support site for Chukchi incidents is identified: although it is observed to occasionally complete mechanical recovery tasks, this site generally completes tasks pertaining to spill tracking, the safety task, and logistics. Dispersants application, the remaining spillage volume recovery strategy that is responsible for addressing the final $3 \%$ of the total volume, is prioritized at secondary sites in the more distant zones. Thus, the coordination strategy, discussed previously, impacts the types of tasks completed for each incident by each response site. In general, the strategy reduces the percentage of follow-on tasks that are completed for all incidents as factors constraining the response are 
diminished (Table 4), by decreasing the number of these tasks being completed from sites closest to the incident locations.

\subsection{Enhanced Network}

CS7: How does the inclusion of additional response sites impact the solution? The stockpile budget variation analysis is examined for the case of an enhanced response network that includes four additional, limited-capability, unmanned storage sites (e.g., budget instances $D_{1}-D_{7}$ ).
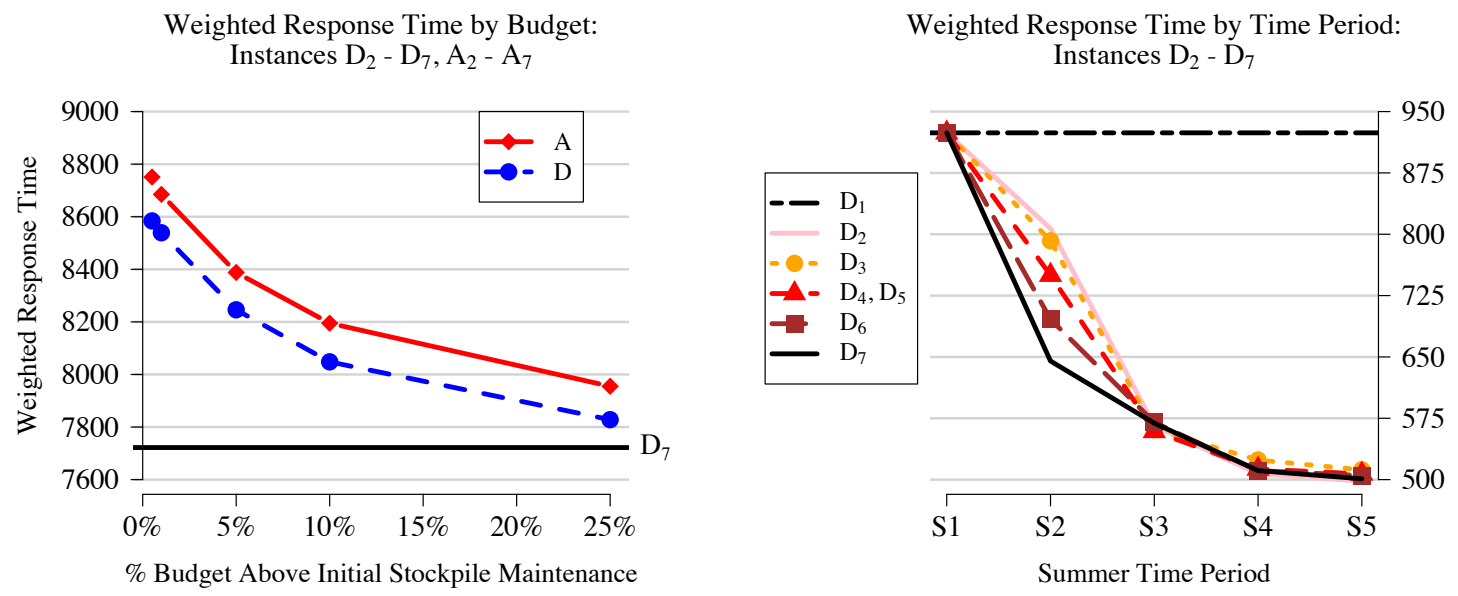

Figure 6: Left: Weighted response times by non-zero budget level for the enhanced network instances (e.g., $D_{2}-D_{7}$ ) compared to the original network instances (e.g., $A_{2}-A_{6}$ ). Budget instance $D_{1}$ (solution: 18630) is omitted for clarity. Right: Weighted response times for the first five Summer time periods for the enhanced network instances. Note that $5 \%$ and $10 \%$ solutions overlap in this figure despite differences in their solutions.

Figure 6 demonstrates that the improvements to weighted response times as the resource allocation budget is increased are similar to the improvements observed for the base network (e.g., budget instances $A_{1}-A_{7}$ ). The improvements to the weighted response times are $2 \%$ on average, but attained at a five-fold increase in maintenance and infrastructure investment costs to stockpile (land-based) resources at these sites. The DEW Line sites primarily stockpiled resources for use within the Chukchi response zone, for the strategies of safety $\left(T S_{1}\right)$, mechanical recovery $\left(T S_{2}\right)$, and logistics $\left(T S_{5}\right)$. Although these stockpiling decisions resulted in reduced support from the more distant zones (e.g., $B F 2, B F 3, C H 2, C H 3$ ), the most distant zones $(B F 5, C H 5)$ display an increase in mobilized resources for most incidents in both regions, which indicates a reduced need to stockpile centrally within the response network. All of the observations in this section are undermined by the increased burden of refurbishing and maintaining the DEW Line sites, the political challenges that might exist, and the elevated risk of theft of equipment stockpiled within unmanned storage sites (as noted by domain experts). Decision-makers should consider these factors prior to selecting unmanned storage sites for inclusion within the Arctic response network, particularly from the DEW Line system. 


\section{Summary and Conclusions}

This paper proposed a novel dynamic network expansion problem that can be applied to a remote oil spill response (OSR) network. The model, its assumptions, and data requirements were assessed by subject matter experts in the U.S. Coast Guard and a major Oil Spill Response Organization in the context of OSR logistics to support energy exploration initiatives in the U.S. Arctic. Computational analyses were developed to derive policy insights pertaining to infrastructure investment decisions that the U.S. government could implement in order to improve OSR response times in this region. Together, the findings provide empirical support for the often-heard adage that early response deployment and budget increases have the greatest positive impact on improved response times, and by extension, on response effectiveness. Most importantly, however, decision-makers now have modeling and trade-off visibility for timing, budget, and resource allocation 'tipping points,' the points after which additional budget and resources have lower marginal benefits. Decision-makers in the Arctic and similar remote regions now have the capability to examine consequences of missed deadlines in terms of needing to complete a different response task to mitigate the impact of a missed deadline. Finally, the order in which effective coordination activities between oil spill response sites occur can now also be visualized. The visibility of tradeoff, timing, and cross-over points are new decision support capabilities for Arctic oil spill response decision-makers.

Relatively inexpensive stockpile and infrastructure investments to the present-day network could result in significant improvements to weighted response times. However, there may exist a point at which the gains resulting from investments are only marginal, indicating that certain sites' capabilities and any process that can delay deployments are conditions which limit the system in ways that are not purely economic. Conditions that limit a site's maximal utilization, such as insufficient personnel or physical access to an incident, and those contributing to response delays, such as completion of human safety tasks or government permit-approval processes for other tasks, can result in reduced returns on investment for improvements made to the most remote response sites. Decision-makers might test for the presence and severity of these conditions in order to assess the capability of remote response networks and promote cost-effective solutions.

Stockpile and infrastructure decisions should promote the completion of critical, time-consuming tasks by mobilizing and deploying resources from remote response sites which are closest to areas of elevated risk of an oil spill incident. These sites can work in conjunction with neighbors within nearby response zones in order to overcome limitations present in the system, by stockpiling resources for certain, different tasks in each site. Sites are preferred based on their ability to handle specific roles rather than how central they are in the response network. Centrality of response sites within the response network has a temporal quality: centrality is less important early in the response and becomes more important as supply chains become energized.

Coordination strategies between response sites mobilizing oil spill response resources have a particular

role in oil spill response, as they reduce the percentage of follow-on tasks required. Cooperative behavior, 
in terms of sharing and shipping resources between response sites, should be further explored, to develop empirical support and modeling capability for international oil spill response cooperation.

The inclusion of unmanned storage locations by way of refurbished DEW Line sites could provide small improvements to incident response times, but at significant cost. Decision-makers should consider whether remote storage locations, and perhaps the DEW Line sites in particular, are cost effective measures to improve the response network.

This work should be extended so that modeling remote OSR networks can be applicable to a wider variety of settings. One extension should consider the impacts due to uncertainty in resource transit times, on-hand resources, safety task completion time, and task deadlines. Examination of these uncertainties could yield task completion policies that incorporate climatological factors in order to provide a framework for organizing response operations under a variety of real-world circumstances. This extension could also explore factors influencing the task weights, or new objective function formulations that model different definitions of weighted response times. Another extension should consider how multinational operators can work in tandem to develop an international response network and task completion policies that are impacted by the constituent member states. For instance, it could be important to examine situations where United States and Canada respond jointly to oil spill incidents in the Beaufort Sea. Finally, future work should explore algorithmic and/or heuristic development for problems of increased complexity and size in order to reduce the difficulty and yield quality solutions in a reasonable time frame.

\section{Acknowledgments}

This research was supported by the U.S. Department of Homeland Security, Command, Control and Interoperability Center for Advanced Data Analysis (CCICADA), Dr. Fred Roberts, and the McDevitt Foundation. The authors would like to acknowledge the support and contributions of the U.S. Coast Guard in this work, particularly those of Rear Admiral Thomas Ostebo, USCG (retired); Vice Admiral Brian Salerno, USCG (retired); Rear Admiral Daniel Abel, USCG; CDR Paul M. Stocklin, USCG; CAPT Jamie Robinson, USCG; and Mark Everett from Coast Guard District 17 in Juneau, Alaska; CDR Michael Goldschmidt, USCG; and David Boyd and Chuck Turner from Coast Guard Pacific Area Command 7 in Alameda, California; Mike Lehocky and Christine Hansen from the U.S. Coast Guard Research and Development Center in New London, Connecticut; as well as those of CAPT Claudia Gelzer, USCG; CAPT Julia Hein, USCG; and LT Sara Booth Thompson, USCG from U.S. Coast Guard Headquarters; in this work. The support and assistance of Lee Majors and Chris Hall, Alaska Clean Seas is also gratefully acknowledged. Involvement of Coast Guard employees does not constitute endorsement of this project, or represent the official positions of the Coast Guard, Department of Homeland Security, the U.S. Government, or any of its employees. In addition, the work of Thomas C. Sharkey was supported by the U.S. National Science Foundation under CMMI-1254258. 
Aagaard, K., Pease, C. H., Roach, A. T., and Salo, S. A. (1989). Beaufort Sea mesoscale circulation study final report. Technical report, National Oceanic and Atmospheric Administration.

Alaska Clean Seas (2012). Alaska Clean Seas Technical Manual Volume 1 Tactics Descriptions. http: //www.alaskacleanseas.org/Volume_1_Tactics.pdf. Last accessed 25 Mar 2015.

Alaska Clean Seas (2013). Alaska Clean Seas Technical Manual Volume 2 Map Atlas. http://www. alaskacleanseas.org/Volume_2_Maps.pdf. Last accessed 25 Mar 2015.

Averbakh, I. (2012). Emergency path restoration problems. Discrete Optimization, 9(1):58 - 64.

Averbakh, I. and Pereira, J. (2012). The flowtime network construction problem. IIE Transactions, 44(8):681 694.

Averbakh, I. and Pereira, J. (2015). Network construction problems with due dates. European Journal of Operational Research, 244(3):715 - 729.

Baxter, M., Elgindy, T., Ernst, A. T., Kalinowski, T., and Savelsbergh, M. (2014). Incremental network design with shortest paths. European Journal of Operational Research, 238(3):675 - 684.

Belardo, S., Harrald, J., Wallace, W. A., and Ward, J. (1984). A partial covering approach to siting response resources for major maritime oil spills. Management Science, 30(10):1184-1196.

Bird, K. J., Charpentier, R. R., Gautier, D. L., Houseknecht, D. W., Klett, T. R., Pitman, J. K., Moore, T. E., Schenk, C. J., Tennyson, M. E., and Wandrey, C. J. (2008). Circum-Arctic resource appraisal; estimates of undiscovered oil and gas north of the Arctic Circle: U.S. Geological Survey Fact Sheet 2008-3049. http://pubs.usgs.gov/fs/2008/3049/. Last accessed 30 Apr 2015.

Brigham, L. (2010). The Fast-Changing Maritime Arctic. Proceedings of the U.S. Naval Institute, 136(5):54 59.

Cavdaroglu, B., Hammel, E., Mitchell, J. E., Sharkey, T. C., and Wallace, W. A. (2013). Integrating restoration and scheduling decisions for disrupted interdependent infrastructure systems. Annals of Operations Research, 203(1):279-294.

Charnes, A., Cooper, W. W., Harrald, J., Karwan, K. R., and Wallace, W. A. (1976). A goal interval programming model for resource allocation in a marine environmental protection program. Environmental Economics and Management, 3(4):347-362.

Charnes, A., Cooper, W. W., Karwan, K. R., and Wallace, W. A. (1979). A chance-constrained goal programming model to evaluate response resources for marine pollution disasters. Environmental Economics and Management, 6(3):244-274. 
Danielson, S., Aagaard, K., Weingartner, T., Martin, S., Winsor, P., Gawarkiewicz, G., and Quadfasel, D. (2006). The St. Lawrence polynya and the Bering Shelf circulation: New observations and a model comparison. Journal of Geophysical Research, 111(C09023):1-18.

Forbes, J. A. (2015). Restoration and humanitarian aid delivery on interdependent transportation and communication networks after an extreme event. Master's thesis, Department of Operational Sciences, Air Force Institute of Technology, Wright-Patterson Air Force Base, Ohio.

Gawande, K. and Wheeler, T. (1999). Measures of effectiveness for governmental organizations. Management Science, 45(1):42-58.

Grabowski, M., You, Z., Song, H., Wang., H., and Merrick, J. (2010). Sailing on Friday: Developing the Link Between Safety Culture and Performance in Safety-Critical Systems. IEEE Systems, Man and Cybernetics, Part A: Systems and Humans, 40(2):263-284.

Hamilton, L., White, D., Lammers, R., and Myerchin, G. (2012). Population, climate, and electricity use in the Arctic integrated analysis of Alaska community data. Population and Environment, 33(4):269 - 283.

Harrald, J., Grabowski, M., Van Dorp, R., and Merrick, J. (1999). Assessing Risk in the Washington State Ferry System. In Annual Conference of the International Emergency Management Society, pages 427-437.

Hongxia, C., Huiwu, W., Qi, S., Daolong, W., and Na, L. (2013). Ocean current observation and spectrum analysis in central Chukchi Sea during the summer of 2008. Acta Oceanologica Sinica, 32(3):10-18.

Huntington, H., Daniel, R., Hartsig, A., Harun, K., Heiman, M., Meehan, R., Noongwook, G., Pearson, L., Prior-Parks, M., Robards, M., and Stetson, G. (2015). Vessels, Risks, and Rules: Planning for Safe Shipping in Bering Strait. Marine Policy, 51:119 - 127.

Iakovou, E., Ip, C. M., Douligeris, C., and Korde, A. (1997). Optimal location and capacity of emergency cleanup equipment for oil spill response. European Journal of Operational Research, 96(1):72-80.

Kalinowski, T., Matsypura, D., and Savelsbergh, M. (2015). Incremental network design with maximum flows. European Journal of Operational Research, 242(1):51 - 62.

MBC Applied Environmental Sciences (2003). Physical Oceanography of the Beaufort Sea - Workshop Proceedings. Technical report, Anchorage, AK.

Merrick, J., Van Dorp, R., Harrald, J., Mazzuchi, T., Spahn, J. E., and Grabowski, M. (2000). A systems approach to managing oil transportation risk in Prince William Sound. Systems Engineering, 3(3):128-142.

National Academy of Sciences (2014). Responding to Oil Spills in the U.S. Arctic Marine Environment. National Academies Press, Washington, D.C. 
National Petroleum Council (2015). Arctic Potential: Realizing the Promise of U.S. Arctic Oil and Gas Resources. http://www.npcarcticpotentialreport.org. Last accessed 4 Jan 2016.

Nurre, S. G., Cavdaroglu, B., Mitchell, J. E., Sharkey, T. C., and Wallace, W. A. (2012). An integrated network design and scheduling problem. European Journal of Operational Research, 223(3):794-806.

Nurre, S. G. and Sharkey, T. C. (2014). Integrated network design and scheduling problems with parallel identical machines: complexity analysis and dispatching rules. Networks, 63(4):306-326.

Papp, R. J. (2013). United States Coast Guard Arctic Strategy. http://www .uscg.mil/seniorleadership/ DOCS/CG_Arctic_Strategy.pdf. Last accessed 25 Mar 2015.

Pinedo, M. L. (2008). Scheduling: Theory, Algorithms, and Systems. Springer Publishing Company, Incorporated, New York, 3rd edition.

Psaraftis, H. N., Tharakan, G. G., and Ceder, A. (1986). Optimal response to oil spills: the strategic decision case. Operations Research, 34(2):203-217.

Qiu, J. and Sharkey, T. C. (2013). Integrated dynamic single facility location and inventory planning problems. IIE Transactions, 45(8):883-895.

Romeijn, H. E., Sharkey, T. C., Shen, Z. J., and Zhang, J. (2010). Integrating facility location and production planning problems. Networks, 55(2):78-89.

Sharkey, T. C., Geunes, J., Romeijn, H. E., and Shen, Z. J. (2011). Exact algorithms for integrated production planning and facility location problems. Naval Research Logistics, 58(5):419-436.

Srinivasa, A. V. and Wilhelm, W. E. (1997). A procedure for optimizing tactical response in oil spill clean up operations. European Journal of Operational Research, 102(3):554-574.

United States Coast Guard (2013). Guidelines for the U.S. Coast Guard Oil Spill Removal Organization Classification Program. http://www. uscg.mil/hq/nsfweb/nsf/nsfcc/ops/ResponseSupport/RRAB/osro_ files/0313Classification\%20Guidelines.pdf. Last accessed 25 Mar 2015.

U.S. Department of Homeland Security (2013). Budget-in-Brief Fiscal Year 2014. https: //www.dhs.gov/sites/default/files/publications/MGMT/FY\% $202014 \% 20 B I B \% 20-\% 20$ FINAL $\% 20-508 \%$ 20Formatted\%20(4).pdf. Last accessed 30 Apr 2015.

U.S. Department of the Interior, Bureau of Ocean Energy Management (2011a). 2012 Shell Revised Beaufort Sea EP EA. http://www.boem.gov/uploadedFiles/BOEM/Oil_and_Gas_Energy_Program/Plans/ Regional_Plans/Alaska_Exploration_Plans/2012_Shell_Beaufort_EP/EA_Shell2012CamdenBay. pdf. Last accessed 25 Mar 2015. 
U.S. Department of the Interior, Bureau of Ocean Energy Management (2011b). 2012 Shell Revised Chukchi Sea EP EA. http://www.boem.gov/uploadedFiles/2011_1214_FINAL_2012ChukchiSeaEA.PDF. Last accessed 25 Mar 2015.

Verma, M., Gendreau, M., and Laporte, G. (2013). Optimal location and capability of oil-spill response facilities for the south coast of Newfoundland. Omega, 41(5):856-867. 